\title{
Streptomyces colonosanans sp. nov., A Novel Actinobacterium Isolated from Malaysia Mangrove Soil Exhibiting Antioxidative Activity and Cytotoxic Potential against Human Colon Cancer Cell Lines
}

OPEN ACCESS

Edited by:

Dongsheng Zhou,

Beijing Institute of Microbiology and

Epidemiology, China

Reviewed by:

Andrei A. Zimin,

Institute of Biochemistry and

Physiology of Microorganisms (RAS),

Russia

Antoine Danchin

Institut de Cardiométabolisme et

Nutrition (ICAN), France

*Correspondence:

Bey-Hing Goh

goh.bey.hing@monash.edu

Learn-Han Lee

lee.learn.han@monash.edu:

leelearnhan@yahoo.com

Specialty section:

This article was submitted to Antimicrobials, Resistance and

Chemotherapy,

a section of the journal

Frontiers in Microbiology

Received: 13 February 2017

Accepted: 01 May 2017

Published: 16 May 2017

Citation:

Law JW-F, Ser H-L, Duangjai A, Saokaew S, Bukhari SI, Khan TM, Mutalib N-SA, Chan K-G, Goh B-H and Lee L-H (2017) Streptomyces

colonosanans sp. nov., A Novel

Actinobacterium Isolated from Malaysia Mangrove Soil Exhibiting Antioxidative Activity and Cytotoxic

Potential against Human Colon Cancer Cell Lines.

Front. Microbiol. 8:877. doi: 10.3389/fmicb.2017.00877
Jodi Woan-Fei Law ${ }^{1}$, Hooi-Leng Ser ${ }^{1}$, Acharaporn Duangjai ${ }^{2,3}$, Surasak Saokaew 1,3, 4 , Sarah I. Bukhari ${ }^{5}$, Tahir M. Khan ${ }^{1,6}$, Nurul-Syakima Ab Mutalib ${ }^{7}, K_{\text {Kok-Gan Chan }}{ }^{8}$, Bey-Hing Goh ${ }^{1,3 *}$ and Learn-Han Lee ${ }^{1,3 *}$

${ }^{1}$ Novel Bacteria and Drug Discovery Research Group, School of Pharmacy, Monash University Malaysia, Bandar Sunway, Malaysia, ${ }^{2}$ Division of Physiology, School of Medical Sciences, University of Phayao, Phayao, Thailand, ${ }^{3}$ Center of Health Outcomes Research and Therapeutic Safety, School of Pharmaceutical Sciences, University of Phayao, Phayao, Thailand, ${ }^{4}$ Faculty of Pharmaceutical Sciences, Pharmaceutical Outcomes Research Center, Naresuan University, Phitsanulok, Thailand, ${ }^{5}$ Department of Pharmaceutics, College of Pharmacy, King Saud University, Riyadh, Saudi Arabia, ${ }^{6}$ Department of Pharmacy, Absyn University Peshawar, Peshawar, Pakistan, ${ }^{7}$ UKM Medical Molecular Biology Institute, UKM Medical Centre, University Kebangsaan Malaysia, Kuala Lumpur, Malaysia, ${ }^{8}$ Division of Genetics and Molecular Biology, Faculty of Science, Institute of Biological Sciences, University of Malaya, Kuala Lumpur, Malaysia

Streptomyces colonosanans MUSC 93J', a novel strain isolated from mangrove forest soil located at Sarawak, Malaysia. The bacterium was noted to be Gram-positive and to form light yellow aerial and vivid yellow substrate mycelium on ISP 2 agar. The polyphasic approach was used to determine the taxonomy of strain MUSC 93J and the strain showed a range of phylogenetic and chemotaxonomic properties consistent with those of the members of the genus Streptomyces. Phylogenetic and 16S rRNA gene sequence analysis indicated that closely related strains include Streptomyces malachitofuscus NBRC $13059^{\top}$ (99.2\% sequence similarity), Streptomyces misionensis NBRC $13063^{\top}$ (99.1\%), and Streptomyces phaeoluteichromatogenes NRRL 5799 (99.1\%). The DNA-DNA relatedness values between MUSC 93J $\mathrm{J}^{\top}$ and closely related type strains ranged from $14.4 \pm 0.1$ to $46.2 \pm 0.4 \%$. The comparison of BOX-PCR fingerprints indicated MUSC 93J $J^{\top}$ exhibits a unique DNA profile. The genome of MUSC 93J consists of 7,015,076 bp. The DNA G + C content was determined to be $69.90 \mathrm{~mol} \%$. The extract of strain MUSC 93J $\mathrm{J}^{\top}$ was demonstrated to exhibit potent antioxidant activity via ABTS, metal chelating, and SOD assays. This extract also exhibited anticancer activity against human colon cancer cell lines without significant cytotoxic effect against human normal colon cells. Furthermore, the chemical analysis of the extract further emphasizes the strain is producing chemo-preventive related metabolites. Based on this polyphasic study of MUSC 93J', it is concluded that this strain represents a novel species, for which the name Streptomyces colonosanans sp. nov. is proposed. The type strain is MUSC 93J $J^{\top}\left(=\mathrm{DSM} 102042^{\top}=\right.$ MCCC $\left.1 \mathrm{~K}^{\top} 2298^{\top}\right)$.

Keywords: Streptomyces colonosanans, actinobacteria, mangrove, antioxidant, cancer 


\section{INTRODUCTION}

The discovery of new and useful compounds is constantly in need for the prevention and/or treatment of diseases. Nature has been an interesting source of many useful compounds that have important applications in various fields such as pharmacy, medicine, and biochemistry (Burja et al., 2001; Karikas, 2010). Researchers have been exploring natural sources such as plants and microorganisms for the discovery of novel drugs. Microorganisms have gained increasing attention in drug discovery and many studies revealed that microorganisms from different ecosystems have shown some potentials for human use as many interesting compounds have been derived from them (Burja et al., 2001; Chin et al., 2006).

In the field of microbial drug discovery, Actinobacteria strains have been greatly explored due to their ability to produce diverse bioactive secondary metabolites; accounting for $45 \%$ of all discovered bioactive microbial metabolites (Sharma and Shah, 2014). Particularly, the dominant genus of this phylum which is Streptomyces have a significant contribution to mankind (Azman et al., 2015). The genus Streptomyces is proposed by Waksman and Henrici (1943) and it is a group of Gram positive bacteria comprised $\sim 780$ species with validly published names (http://www.bacterio.cict.fr/). Members of this genus are producers of more than $75 \%$ of the naturally occurring antibiotics (Kinkel et al., 2014; Lee et al., 2014e; Ser et al., 2015a). Other than antibiotics, Streptomyces bacteria are prolific producers of various compounds with important biological activities such as antifungal, anticancer, antioxidant, and immunosuppressive activities (Kino et al., 1987; Rashad et al., 2015; Ser et al., 2016a; Law et al., 2017). It is known that exploring new taxa is one of the successful strategies that can lead to the discovery of therapeutic agents (Williams, 2009; Ser et al., 2016c). In previous drug screening programs, it is unfortunate that the screening of novel Actinobacteria from terrestrial source have resulted in inefficient rediscovery of known bioactive compounds (Ser et al., 2016c). Therefore, this highlighted the need to discover novel Actinobacteria from new or under explored area such as the mangrove environments.

Mangrove environments consists of special woody plant area mainly located in intertidal zones of estuaries, deltas, lagoons, backwaters, creeks, marshes, tropical, and subtropical coastal regions (Mangamuri et al., 2012; Ser et al., 2015a). Mangrove is one of the world's most dynamic environments which occupies millions of hectors across the world coastal areas and it has been a habitat to various flora and fauna of terrestrial, freshwater, and marine species (Mangamuri et al., 2012; Lee et al., 2014e). According to the report by Giri et al. (2011), the largest extent of mangroves is found in Asia; and Malaysia is one of the most mangrove-rich countries in Asia. Additionally, one of the least disturbed mangrove areas in Malaysia is situated at the state of Sarawak, in which most of its mangrove forests are still in pristine condition (Ashton and Macintosh, 2002). Hence, this provides a great opportunity to explore the actinobacterial population present in these mangrove forests.

Owing to the presence of various microbial enzymatic and metabolic activities, the mangrove ecosystem is highly rich in nutrient and organic matter that in turn facilitates the rapid development of species diversity in response to environmental variation (Satheeja and Jebakumar, 2011; Mangamuri et al., 2012). Furthermore, this ecosystem experiences constant fluctuations in salinity and tidal gradient that could trigger metabolic pathway adaptations and possibly lead to the production of pharmaceutically important metabolites. Hence, there are growing interests in the utilization of mangrove microorganism resources and this have subsequently led to the discovery of novel Streptomyces (Hong et al., 2009; Lee et al., 2014d,e).

In recent studies, researchers have successfully identified a number of novel Streptomyces from mangrove environments in different countries. For examples, Streptomyces avicenniae (Xiao et al., 2009), Streptomyces xiamenensis (Xu et al., 2009), Streptomyces sanyensis (Sui et al., 2011), and Streptomyces qinglanensis ( $\mathrm{Hu}$ et al., 2012) from mangrove environments in China, Streptomyces sundarbansensis (Arumugam et al., 2011) from mangrove environments in India, and Streptomyces pluripotens (Lee et al., 2014d), Streptomyces mangrovisoli (Ser et al., 2015b), Streptomyces humi (Zainal et al., 2016), Streptomyces antioxidans (Ser et al., 2016c), and Streptomyces malaysiense (Ser et al., 2016b) from mangrove environments in Malaysia. In addition, several studies also reported that mangrove Streptomyces are capable of producing antioxidant and anticancer agents (Ser et al., 2015a, 2016b,c; Tan et al., 2015). Thus, this prompted the investigation of Streptomyces from underexplored mangrove forest in Sarawak.

As a matter of fact, the current global burden of cancer is increasing continuously and this is mainly due to increasing urbanization, followed by the changes in environmental conditions and lifestyle (Karikas, 2010; Ser et al., 2016b; Siegel et al., 2016). Over the years, natural compounds play a relevant role in cancer therapy and prevention (Nobili et al., 2009). Several anticancer agents that have been successfully derived from Streptomyces include aclarubicin, bleomycin, doxorubicin, mitomycin C, and pentostatin (Tan et al., 2006, 2015). Besides, the knowledge acquired throughout years of research conducted in cancer biology has emphasized the cancer initiation and progression is mainly associated with oxidative stress- a condition characterized by elevated amounts of free radicals (Reuter et al., 2010; Ser et al., 2016b). Oxidative stress is known to cause modification or damage to important cellular macromolecules including DNA which could dramatically increase the risk of cancer (Reuter et al., 2010; Ser et al., 2015a, 2016b; Tan et al., 2015). Meanwhile, antioxidant is acknowledged to play important role in biological system. It exerts its scavenging ability to neutralize the free radicals and thus preventing deleterious effects of excessive free radicals during occurrence of oxidative stress (Ser et al., 2015a, 2016b). In view of the importance of antioxidant, efforts have been made to search for effective natural antioxidants. A number of antioxidants have been derived from Streptomyces such as carazostatin (Kato et al., 1989), antiostatins $A_{1}$ to $A_{4}$ and $B_{2}$ to $B_{5}$ (Mo et al., 1990), carbazoquinocins A to F (Tanaka et al., 1995), and benthocyanins A, B, and C (Shin-ya et al., 1991; Shinya et al., 1993). 
This study explores novel Streptomyces strains present in soil samples collected from the mangrove forest located at Kuching, Sarawak. A novel strain, MUSC $93 \mathrm{~J}^{\mathrm{T}}$ was discovered and polyphasic approach demonstrated that MUSC 93J $\mathrm{J}^{\mathrm{T}}$ represents a novel species of the Streptomyces genus, for which the name Streptomyces colonosanans sp. nov. is proposed. With the advancement of next generation sequencing (NGS) technology, the genome of MUSC $93 \mathrm{~J}^{\mathrm{T}}$ was analyzed in this study. The study also aim to investigate the antioxidant and anticancer properties of MUSC 93J ${ }^{\mathrm{T}}$. Furthermore, gas chromatographymass spectrometry (GC-MS) was conducted for chemical analysis of MUSC $93 \mathrm{~J}^{\mathrm{T}}$ extract in order to reveal the active compounds present in the extract. To the best of our knowledge, there is no literature reported so far in regards to the exploration of biological properties of Streptomyces isolated from Sarawak mangrove environments. Therefore, the outcome of this study provides a further in depth understanding on bioprospecting potential of Streptomyces from under-explored region of Malaysia and at the same time granting the solid foundation to support for a further in depth molecular studies on chemopreventive property possessed by Streptomyces colonosanans sp. nov.

\section{MATERIALS AND METHODS}

\section{Isolation and Maintenance of Strain}

Strain MUSC $93 \mathrm{~J}^{\mathrm{T}}$ was isolated from a soil sample collected at site KTTAS $1\left(1^{\circ} 41^{\prime} 48.57^{\prime} \mathrm{N} 110^{\circ} 11^{\prime} 15.30^{\prime \prime} \mathrm{E}\right)$, situated in the mangrove forest of Kuching, state of Sarawak, Malaysia, in June 2015. Samples of the upper $20 \mathrm{~cm}$ topsoil layer (after the top $2-3 \mathrm{~cm}$ of soils removed) were collected using an aseptic metal trowel, placed in sterile Eppendorf tube and stored in $-20^{\circ} \mathrm{C}$. Air-dried soil samples were ground with a mortar and pestle. Selective pretreatment of soil samples was performed using wet heat in sterilized water ( $15 \mathrm{~min}$ at $50^{\circ} \mathrm{C}$; Takahashi et al., 1996). One gram of air-dried soil was mixed with $9 \mathrm{~mL}$ sterilized water and then the suspension was spread onto an isolation medium ISP 2 (Shirling and Gottlieb, 1966) supplemented with cycloheximide $(50 \mathrm{mg} / \mathrm{L})$ and nalidixic acid $(20 \mathrm{mg} / \mathrm{L})$, and incubated at $28^{\circ} \mathrm{C}$ for 14 days. Pure cultures of strain MUSC $93 \mathrm{~J}^{\mathrm{T}}$ were obtained and maintained on ISP 2 agar slants at $28^{\circ} \mathrm{C}$ and stocked in glycerol suspensions $(20 \%, \mathrm{v} / \mathrm{v})$ at $-20^{\circ} \mathrm{C}$.

\section{Genomic and Phylogenetic Analyses}

Genomic DNA extraction for PCR was performed as described by Hong et al. (2009). PCR amplification of the 16S rRNA gene was conducted according to the protocol described by Lee et al. (2014d). The 16S rRNA gene sequence of strain MUSC $93 \mathrm{~J}^{\mathrm{T}}$ was aligned with representative sequences of related type strains in the genus Streptomyces retrieved from the GenBank/EMBL/DDBJ databases using CLUSTAL-X software (Thompson et al., 1997). The alignment was first verified manually and adjusted, followed by construction of phylogenetic trees with neighbor-joining (Saitou and Nei, 1987; Figure 1) and maximum-likelihood algorithms (Felsenstein, 1981; Figure S1), utilizing the MEGA version 6.0 (Tamura et al., 2013). For neighbor-joining algorithm, the evolutionary distances were computed using the Kimura's two-parameter model (Kimura,
1980).The calculations of level of sequence similarity were performed by EzTaxon-e server (http://eztaxon-e.ezbiocloud. net/; Kim et al., 2012). Bootstrap based on 1,000 resampling method of Felsenstein (1985) was used to analyze the stability of the resultant tree topologies.

For DNA-DNA hybridization, the extraction of genomic DNA of strain MUSC $93 \mathrm{~J}^{\mathrm{T}}$, Streptomyces malachitofuscus JCM $4493^{\mathrm{T}}$, Streptomyces misionensis NBRC $13063^{\mathrm{T}}$ and Streptomyces phaeoluteichromatogenes DSM $41898^{\mathrm{T}}$ were conducted according to the protocol described by Cashion et al. (1977). DNA-DNA hybridization was performed by the Identification Service of the DSMZ, Braunschweig, Germany based on the procedure as described by De Ley et al. (1970) with slight modifications according to Huss et al. (1983). The G + C content of strain MUSC 93J ${ }^{\mathrm{T}}$ was determined by HPLC (Mesbah et al., 1989).

BOX-PCR fingerprint analysis was performed for the characterization of strain MUSC $93 \mathrm{~J}^{\mathrm{T}}$ and the closely related strains with the use of primer BOX-A1R $\left(5^{\prime}\right.$ CTACGGCAAGGCGACGCTGACG-3'; Versalovic et al., 1991; Lee et al., 2014b). The BOX-PCR cycling parameters were performed as described by Lee et al. (2014a) and the PCR products were visualized using $2 \%$ agarose gel electrophoresis.

\section{Chemotaxonomic Characteristics}

Biomass and freeze-dried cells for chemotaxonomic studies were obtained after growing in TSB at $28^{\circ} \mathrm{C}$ for 5 days on a rotary shaker. The analyses of peptidoglycan amino acid composition and sugars of strain MUSC $93 \mathrm{~J}^{\mathrm{T}}$ were performed by the Identification Service of the DSMZ using published protocols (Schumann, 2011). Analysis of fatty acids (Sasser, 1990), polar lipids (Kates, 1986), and respiratory quinones were performed by the Identification Service of the DSMZ. Major diagnostic whole cell sugars of strain MUSC 93J ${ }^{\mathrm{T}}$ were obtained according to the description by Whiton et al. (1985) and analyzed by TLC on cellulose plates (Staneck and Roberts, 1974).

\section{Phenotypic Characteristics}

The cultural characteristics of strain MUSC $93 \mathrm{~J}^{\mathrm{T}}$ was determined following growth on ISP 2, ISP 3, ISP 4, ISP 5, ISP 6, and ISP 7 agar (Shirling and Gottlieb, 1966), actinomycetes isolation agar (AIA; Atlas, 1993), starch casein agar (SCA; Küster and Williams, 1964), Streptomyces agar (SA; Atlas, 1993), and nutrient agar (Macfaddin, 2000) at $28^{\circ} \mathrm{C}$ for 14 days. The morphology of strain MUSC $93 \mathrm{~J}^{\mathrm{T}}$ was observed after incubation on ISP 2 agar plate at $28^{\circ} \mathrm{C}$ for $7-14$ days (Figure 2), using Light microscopy (80i, Nikon) and scanning electron microscopy (JEOL-JSM 6400). The designations of colony colors were made according to the ISCC-NBS color charts. Gram staining was carried out by standard Gram reaction and confirmed by using $\mathrm{KOH}$ lysis (Cerny, 1978). The $\mathrm{pH}$ range for growth and $\mathrm{NaCl}$ tolerance were evaluated using tryptic soy broth (TSB). The $\mathrm{pH}$ range tested was between $\mathrm{pH} 4.0$ and 10.0 at an interval of $1 \mathrm{pH}$ unit. The concentration of $\mathrm{NaCl}$ was tested at a range of $0-$ $10 \%(\mathrm{w} / \mathrm{v})$ at intervals of $2 \%$. The effects of temperatures on growth was examined on ISP 2 agar. The temperature range tested for growth was between 4 and $44^{\circ} \mathrm{C}$ at intervals of $4^{\circ} \mathrm{C}$. The growth responses to $\mathrm{pH}, \mathrm{NaCl}$, and temperature were 


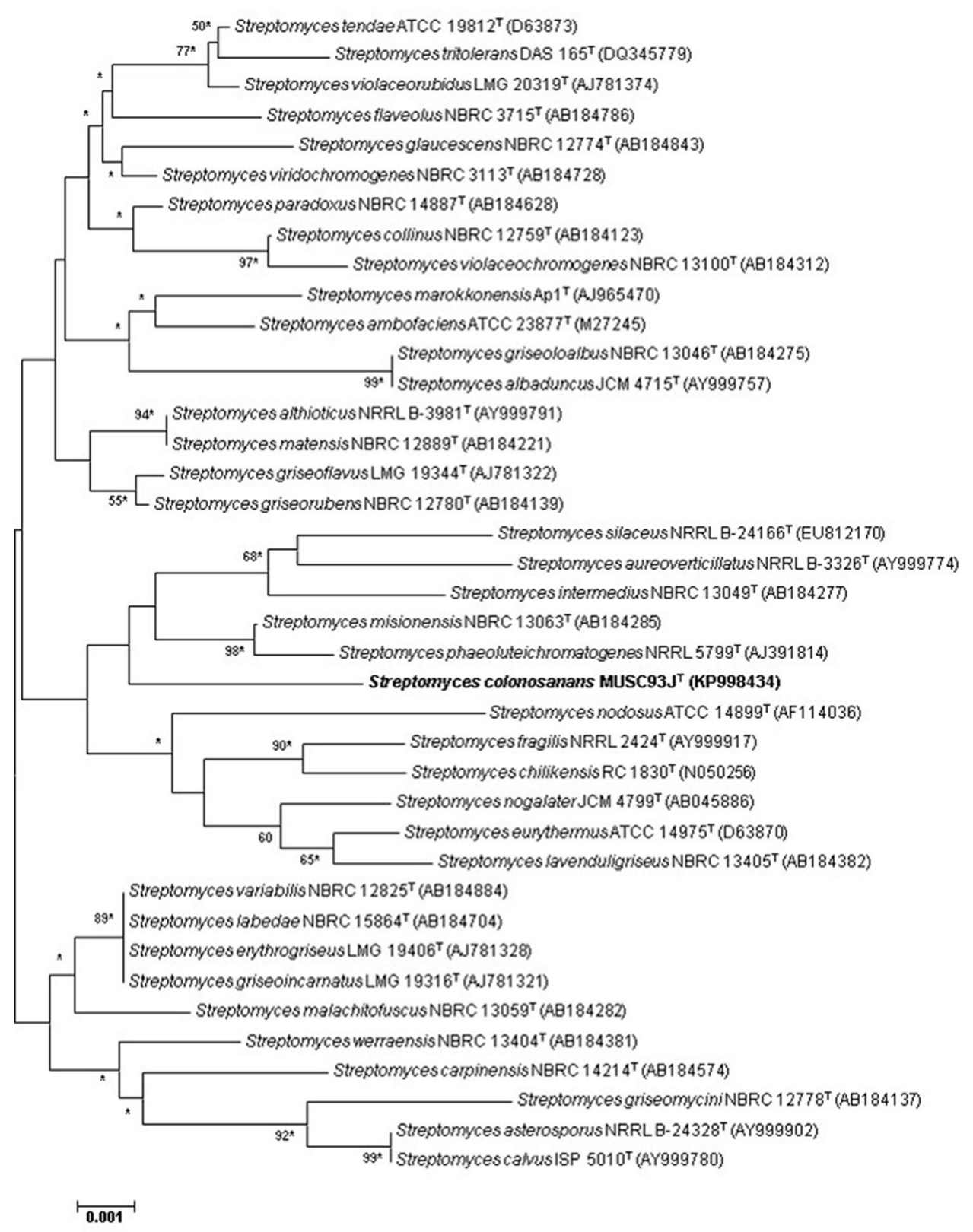

FIGURE 1 | Neighbor-joining phylogenetic tree based on almost complete 16S rRNA sequences (1,490 nucleotides) showing the relationship between strain MUSC $93 \mathbf{J}^{\top}$ and representatives of some other related taxa. Numbers at nodes indicate percentages of 1,000 bootstrap re-samplings, only values above $50 \%$ are shown. Bar, 0.002 substitutions per site. Asterisks indicate that the corresponding nodes were also recovered using the maximum-likelihood tree-making algorithm.

observed for 14 days. The production of melanoid pigments was examined using ISP 7 medium following protocol described by Lee et al. (2014c). Hemolytic activity was examined on blood agar medium containing $5 \%(\mathrm{w} / \mathrm{v})$ peptone, $3 \%(\mathrm{w} / \mathrm{v})$ yeast extract, $5 \%(\mathrm{w} / \mathrm{v}) \mathrm{NaCl}$, and 5\% (v/v) horse blood (Carrillo et al., 1996). Plates were examined for hemolysis after incubation at $32^{\circ} \mathrm{C}$ for 7-14 days. Amylolytic, lipase, cellulase, chitinase, catalase, protease, and xylanase activities were determined by growing cells on ISP 2 medium following protocol as described by Lee et al. (2014c). The presence of clear zones around colonies indicates the potential of isolates for surfactant production. The carbon-source utilization and chemical sensitivity assays were determined using Biolog GenIII MicroPlates (Biolog, USA) according to the manufacturer's instructions.

All of the phenotypic assays mentioned were performed concurrently for strain MUSC $93 \mathrm{~J}^{\mathrm{T}}$, Streptomyces malachitofuscus JCM $4493^{\mathrm{T}}$, Streptomyces misionensis NBRC $13063^{\mathrm{T}}$, and Streptomyces phaeoluteichromatogenes DSM $41898^{\mathrm{T}}$. 


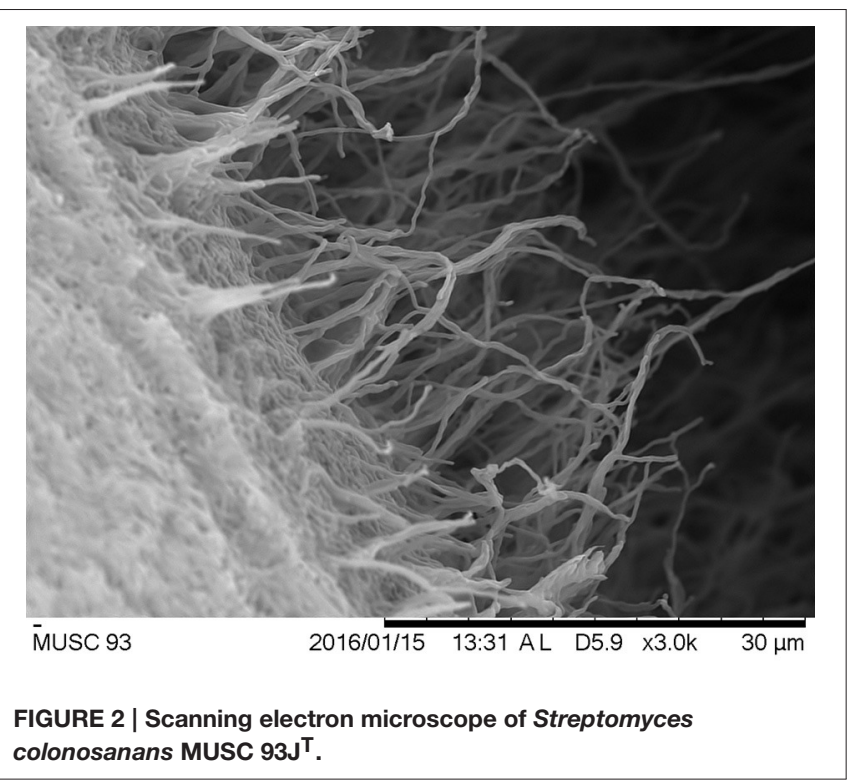

colonosanans MUSC 93J'. solution $(7 \mathrm{mM})$ and potassium persulfate $(2.45 \mathrm{mM})$ for $24 \mathrm{~h}$ before the assay. The absorbance was measured at $743 \mathrm{~nm}$ and the change in radical amount was indicated by the reduction in absorbance value.

\section{Superoxide Anion Scavenging/Superoxide Dismutase (SOD)}

Superoxide anion scavenging /superoxide dismutase (SOD) activity was determined using SOD assay Kit-WST (SigmaAldrich), a commercially available colorimetric microtiter plate method, according to the protocol given by the manufacturer. SOD activity of the extract was determined colorimetrically at $450 \mathrm{~nm}$ as the reduction of the Dojindo's highly water-soluble tetrazolium salt, WST-1 (2-(4-iodophenyl)-3-(4-nitrophenyl)5-(2,4-disulfophenyl)-2H-tetrazolium, monosodium salt) by superoxide anion, $\mathrm{O}_{2}{ }^{-}$. Sample extract solution $(20 \mu \mathrm{L})$ at different concentrations were added to the 96-well-plate, respectively. The reaction solutions were added as described in the protocol and then the plate was incubated at $37^{\circ} \mathrm{C}$ for $20 \mathrm{~min}$ prior to measurement of absorbance at $450 \mathrm{~nm}$ using a microplate reader. The percentage of SOD activity (percentage of WST-1 reduction) was calculated as follows (Tan et al., 2015):

Percentage of SOD activity (\%)

$$
=\frac{((\text { Absorbance of blank } 1-\text { Absorbance of blank } 3)-(\text { Absorbance of sample }- \text { Absorbance of black } 2))}{\text { (Absorbance of blank } 1-\text { Absorbance of blank } 3)} \times 100 \%
$$

\section{Extract Preparation of MUSC $93 \mathbf{J}^{\mathbf{T}}$}

Before fermentation process, strain MUSC $93 \mathrm{~J}^{\mathrm{T}}$ was grown in TSB (Biomerge, Malaysia) as seed medium for 14 days. The fermentation medium, Han's Fermentation Media 1 (HFM1) was autoclaved at $121^{\circ} \mathrm{C}$ for $15 \mathrm{~min}$ prior to experiment (Hong et al., 2009; Lee et al., 2012). The fermentation was conducted in $500 \mathrm{~mL}$ Erlenmeyer flask containing $200 \mathrm{~mL}$ HFM1 (Biomerge, Malaysia) with $200 \mu \mathrm{L}$ seed media added into it and shaking at $200 \mathrm{rpm}$ for $7-10$ days at $28^{\circ} \mathrm{C}$. The resulting Han's Fermentation medium was recovered by centrifugation at $12000 \mathrm{~g}$ for $15 \mathrm{~min}$. The supernatant was filtered and collected, then subjected to freeze drying process. The freeze-dried sample was extracted with methanol for $72 \mathrm{~h}$. The methanol-containing extract was filtered and collected, then subjected to re-extraction under same condition for twice at $24 \mathrm{~h}$ interval. The collected extract was concentrated with extracting solvent evaporated by rotary vacuum evaporator at $40^{\circ} \mathrm{C}$. The final concentrate extract of MUSC 93$]^{\mathrm{T}}$ was collected and suspended in dimethyl sulfoxide (DMSO) as vehicle reagent prior to bioactivity screening assays.

\section{Determination of Antioxidant Activity of MUSC 93 ${ }^{\top}$ Extract Using Different Assays} The 2,2' -Azino-Bis (3-Ethylbenzothiazoline-6-Sulfonic Acid) (ABTS) Assay

The 2,2'-azino-bis (3-ethylbenzothiazoline-6-sulfonic acid) (ABTS) assay was conducted according to the protocol described by Miser-Salihoglu et al. (2013) with some modifications. ABTS radical cation (ABTS.) was produced via reacting ABTS stock

\section{Metal Chelating}

Metal Chelating activity was examined by measuring the formation of $\mathrm{Fe}^{2+}$-ferrozine complex as described in previous study conducted by Manivasagan et al. (2013) with slight modification. $\mathrm{FeSO}_{4}(2 \mathrm{mM})$ was added into the extract followed by the addition of ferrozine $(5 \mathrm{mM})$ to initiate the reaction prior to measurement of absorbance at $562 \mathrm{~nm}$ using spectrophotometer.

\section{Maintenance and Growth Condition of Human Cell Lines}

The human normal colon CCD-18Co cells were maintained in DMEM media supplemented with $10 \%$ fetal bovine serum in a humidified incubator with $5 \% \mathrm{CO}_{2}$ in air at $37^{\circ} \mathrm{C}$ (Ser et al., 2016c). All of the human derived cancer cell lines evaluated in this study were maintained in RPMI (Roswell Park Memorial Institute)-1640 (Gibco) supplemented with 10\% fetal bovine serum and $1 \mathrm{x}$ antibiotic-antimycotic (Gibco) in a humidified incubator with $5 \% \mathrm{CO}_{2}$ in air at $37^{\circ} \mathrm{C}$ (Tan et al., 2015).

\section{Investigation of Cytotoxicity Activity of MUSC 93 $\mathbf{J}^{\top}$ Using \\ 3-(4,5-Dimethylthazol-2yl)-2,5-Diphenyl Tetrazolium-Bromide (MTT) Assay}

For evaluation of cytotoxicity, the human normal colon CCD18Co cells were included in this study, while the human derived cancer cell lines included were colon cancer cell lines: HCT-116, HT-29, Caco-2, and SW480. The cytotoxic activity of MUSC $933^{\mathrm{T}}$ extract was examined using MTT assay following the protocol 
previously described by Williams (1989). The cell viability was determined spectrophotometrically at $570 \mathrm{~nm}$ (with $650 \mathrm{~nm}$ as reference wavelength) using a microplate reader. The percentage of cell viability was calculated as follows:

$$
\begin{aligned}
& \text { Percentage of cell viability (\%) } \\
& \quad=\frac{\text { Absorbance of treated cells }}{\text { Absorbance of untreated cells }} \times 100 \%
\end{aligned}
$$

\section{Gas Chromatography-Mass Spectrometry (GC-MS) Analysis}

GC-MS analysis was performed according to previously developed method with slight modification (Supriady et al., 2015). The analysis was conducted using Agilent Technologies 6980N (GC) equipped with 5979 Mass Selective Detector (MS), with HP-5MS (5\% phenyl methyl siloxane) capillary column of dimensions $30.0 \mathrm{~m} \times 250 \mu \mathrm{m} \times 0.25 \mu \mathrm{m}$ and helium as carrier gas at $1 \mathrm{~mL} / \mathrm{min}$. The column temperature was programmed initially at $40^{\circ} \mathrm{C}$ for $10 \mathrm{~min}$, followed by an increase of $3^{\circ} \mathrm{C} / \mathrm{min}$ to $250^{\circ} \mathrm{C}$ and was kept isothermally for $5 \mathrm{~min}$. The MS was operating at $70 \mathrm{eV}$. The constituents were identified by comparison of their mass spectral data with those from NIST 05 Spectral Library.

\section{Genome Sequencing and Bioinformatics Analysis of MUSC $93 \mathbf{J}^{\top}$}

Genomic DNA of MUSC $93 \mathrm{~J}^{\mathrm{T}}$ was extracted using Masterpure ${ }^{\mathrm{TM}}$ DNA purification kit (Epicentre, Illumina Inc., Madison, WI, USA) followed by RNase (Qiagen, USA) treatment (Ser et al., 2015c, 2016d) Subsequently, the DNA quality was examined using NanoDrop spectrophotometer (Thermo Scientific, Waltham, MA, USA) and a Qubit version 2.0 fluorometer (Life Technologies, Carlsbad, CA, USA). DNA library construction was performed using Nextera ${ }^{\mathrm{TM}}$ DNA Sample Preparation kit (Nextera, USA) and the library quality was validated by Bioanalyzer 2100 high sensitivity DNA kit (Agilent Technologies, Palo Alto, CA). Paired-end sequencing was carried out on MiSeq platform with MiSeq Reagent Kit $2(2 \times$ 250 bp; Illumina Inc., Madison, WI, USA). The paired-end reads were then trimmed and de novo assembled with CLC Genomics Workbench version 7 (CLC bio, Denmark). Gene prediction was carried out using Prodigal version 2.6, whereas rRNA and tRNA were predicted using RNAmmer and tRNAscan SE version 1.21 (Lowe and Eddy, 1997; Lagesen et al., 2007; Hyatt et al., 2010). The assembly was annotated using Rapid Annotation using Subsystem Technology (RAST) and by the NCBI Prokaryotic Genomes Annotation Pipeline (Angiuoli et al., 2008; Aziz et al., 2008). Results of genome sequencing and bioinformatics analysis were presented in the description of Streptomyces colonosanans sp. nov.

\section{Statistical Analysis}

Experiments involved the investigation of antioxidant and cytotoxic activities were done in quadruplicate. Data analysis was performed with SPSS statistical analysis software and the results were expressed as mean \pm standard deviation $(S D)$. One-way analysis of variance (ANOVA) followed by appropriate post-hoc test (Tukey) was performed to determine the significant differences between groups. A difference was considered statistically significant when $p \leq 0.05$.

\section{RESULTS AND DISCUSSION}

\section{Genomic and Phylogenetic Analyses of Strain MUSC 93. $\mathbf{J}^{\top}$}

The nearly complete $16 \mathrm{~S}$ rRNA gene sequence was determined for strain MUSC 93J ${ }^{\mathrm{T}}$ (1490 bp; GenBank/EMBL/DDBJ accession number KP998434) and manual alignment of the sequence was performed with the corresponding partial 16S rRNA gene sequences of the type strains of representative members of the genus Streptomyces retrieved from GenBank/EMBL/DDBJ databases. Phylogenetic trees were constructed based on the 16S rRNA gene sequences to determine the phylogenetic position of this strain (Figure 1 and Figure S1). Phylogenetic analysis exhibited that closely related strains include Streptomyces misionensis NBRC $13063^{\mathrm{T}}$ (99.1\% sequence similarity) and Streptomyces phaeoluteichromatogenes NRRL $5799^{\mathrm{T}}$ (99.1\% sequence similarity), as they formed a distinct clade (Figure 1). The analysis of 16S rRNA gene sequence for strain MUSC 93 $\mathrm{J}^{\mathrm{T}}$ exhibited highest sequence similarity to strain Streptomyces malachitofuscus NBRC $13059^{T}$ (99.2\%), Streptomyces misionensis NBRC $13063^{\mathrm{T}}$ (99.1\%) and Streptomyces phaeoluteichromatogenes NRRL 5799 ${ }^{\mathrm{T}}$ (99.1\%); sequences similarities of $<99.0 \%$ were obtained with the type strains of other species of the genus Streptomyces.

The DNA-DNA relatedness values between strain MUSC $93 \mathrm{~J}^{\mathrm{T}}$ and Streptomyces malachitofuscus JCM $4493^{\mathrm{T}}(14.4 \pm$ $0.1 \%)$, Streptomyces misionensis NBRC $13063^{\mathrm{T}}(46.2 \pm 0.4 \%)$ and Streptomyces phaeoluteichromatogenes DSM $41898^{\mathrm{T}}(20.7 \pm$ $1.0 \%$ ) were significantly below $70 \%$, the threshold value for the delineation of bacterial species (Wayne et al., 1987).

The BOX-PCR results indicated that strain MUSC $93 \mathrm{~J}^{\mathrm{T}}$ exhibited a unique BOX-PCR fingerprint compared with closely related type strains: Streptomyces malachitofuscus JCM $4493^{\mathrm{T}}$, Streptomyces misionensis NBRC $13063^{\mathrm{T}}$, and Streptomyces phaeoluteichromatogenes DSM $41898^{\mathrm{T}}$ (Refer to Figure S2). These results are in line with results of phylogenetic analysis and DNA-DNA hybridizations, which demonstrate that strain MUSC $93 \mathrm{~J}^{\mathrm{T}}$ represents a novel species in the genus Streptomyces.

\section{Chemotaxonomic Analyses of Strain MUSC 93. $\mathbf{J}^{\mathbf{T}}$}

The fatty acids profiles of strain MUSC $93 \mathrm{~J}^{\mathrm{T}}$ and closely related type strains are presented in Table 1. The major cellular fatty acids in MUSC $93 \mathrm{~J}^{\mathrm{T}}$ were identified as anteiso$\mathrm{C}_{15: 0}(23.1 \%), \mathrm{C}_{16: 0}(18.6 \%)$, and iso- $\mathrm{C}_{16: 0}$ (15.1\%). The fatty acids profile of MUSC $93 \mathrm{~J}^{\mathrm{T}}$ is consistent with those of closely related phylogenetic neighbors such as Streptomyces malachitofuscus JCM $4493^{\mathrm{T}}$, Streptomyces misionensis NBRC $13063^{\mathrm{T}}$, and Streptomyces phaeoluteichromatogenes DSM $41898^{\mathrm{T}}$, which contain anteiso- $\mathrm{C}_{15: 0}(12.6-40.1 \%)$ and iso- $\mathrm{C}_{16: 0}(14.4-$ $18.3 \%$ ) as major fatty acids (Table 1). However, the fatty acid profile of MUSC $93 \mathrm{~J}^{\mathrm{T}}$ was quantitatively different from those 
TABLE 1 | Cellular fatty acid composition of strain MUSC $93 \mathrm{~J}^{\top}$ and its closely related Streptomyces species.

\begin{tabular}{|c|c|c|c|c|}
\hline Fatty acid & 1 & 2 & 3 & 4 \\
\hline iso- $\mathrm{C}_{12: 0}$ & 0.1 & 0.1 & - & - \\
\hline $\mathrm{C}_{12: 0}$ & 0.1 & - & - & - \\
\hline iso- $\mathrm{C}_{13: 0}$ & 0.3 & 0.4 & 0.1 & 0.2 \\
\hline anteiso- $\mathrm{C}_{13: 0}$ & 0.3 & 0.2 & 0.3 & - \\
\hline iso- $\mathrm{C}_{14: 0}$ & 5.4 & 2.5 & 1.8 & 4.8 \\
\hline $\mathrm{C}_{14: 0}$ & 1.1 & 0.4 & 0.2 & 0.2 \\
\hline iso- $\mathrm{C}_{15: 0}$ & 9.6 & 17.5 & 7.2 & 12.3 \\
\hline anteiso- $\mathrm{C}_{15: 0}$ & 23.1 & 12.6 & 40.1 & 35.5 \\
\hline$C_{15: 1} w 6 c$ & 0.2 & 0.1 & - & - \\
\hline $\mathrm{C}_{15: 0}$ & 2.3 & 1.9 & 0.7 & 1.6 \\
\hline iso- $\mathrm{C}_{16: 1} \mathrm{H}$ & 0.6 & 2.0 & 1.6 & 1.3 \\
\hline iso- $\mathrm{C}_{16: 0}$ & 15.1 & 18.3 & 14.4 & 17.7 \\
\hline $\mathrm{C}_{16: 1}$ Cis 9 & - & - & 1.3 & 0.7 \\
\hline $\mathrm{C}_{16: 0}$ & 18.6 & 7.9 & 4.0 & 3.4 \\
\hline iso- $\mathrm{C}_{17: 1} \mathrm{w} 9 \mathrm{c}$ & 1.3 & 7.9 & - & - \\
\hline anteiso- $\mathrm{C}_{17: 1} \mathrm{w} 9 \mathrm{c}$ & 1.1 & 2.6 & - & - \\
\hline anteiso- $\mathrm{C}_{17: 1} \mathrm{C}$ & - & - & 4.1 & 2.8 \\
\hline iso- $\mathrm{C}_{17: 0}$ & 3.4 & 8.6 & 2.4 & 3.5 \\
\hline anteiso- $\mathrm{C}_{17: 0}$ & 7.6 & 8.8 & 19.3 & 13.4 \\
\hline $\mathrm{C}_{17: 1} \mathrm{w} 8 \mathrm{c}$ & 0.7 & 1.2 & - & - \\
\hline $\mathrm{C}_{17: 1}$ Cis 9 & - & - & 0.1 & 0.2 \\
\hline $\mathrm{C}_{17: 0}$ CYCLO & 0.9 & 0.2 & 0.4 & 0.3 \\
\hline $\mathrm{C}_{17: 0}$ & 1.6 & 1.2 & 0.2 & 0.2 \\
\hline $\mathrm{C}_{17: 0}$ 10-Methyl & - & 0.3 & - & - \\
\hline iso- $_{18: 1} \mathrm{H}$ & - & 0.3 & - & - \\
\hline iso- $\mathrm{C}_{18: 0}$ & 0.3 & 0.2 & - & - \\
\hline $\mathrm{C}_{18: 1} \mathrm{w} 9 \mathrm{c}$ & - & 0.2 & - & - \\
\hline $\mathrm{C}_{18: 1} \mathrm{w} 7 \mathrm{c}$ & 0.2 & 0.2 & - & - \\
\hline $\mathrm{C}_{18: 0}$ & 0.6 & 0.1 & - & - \\
\hline
\end{tabular}

Strains: 1, Streptomyces colonosanans MUSC $93 \mathrm{~J}^{T} ; 2$, Streptomyces malachitofuscus JCM 4493'; 3, Streptomyces misionensis NBRC 13063 ${ }^{T} ; 4$, Streptomyces phaeoluteichromatogenes DSM $41898^{T}$. -, $<0.1 \%$ or not detected. All data are obtained concurrently from this study.

of these type strains; for instance, the anteiso- $C_{15: 0}(23.1 \%)$ was found to be predominant in strain MUSC $93 \mathrm{~J}^{\mathrm{T}}$, but the amount of anteiso- $\mathrm{C}_{15: 0}$ was much lesser (12.6\%) in Streptomyces malachitofuscus JCM $4493^{\mathrm{T}}$ (Table 1).

Based on the results of the polar lipids analysis, strain MUSC 93 $\mathrm{J}^{\mathrm{T}}$ showed the presence of aminolipid, diphosphatidylglycerol, lipid, phospholipid, phosphatidylinositol, phosphatidylethanolamine, and phosphoglycolipid. The differences in polar lipid profiles showed that MUSC $93 \mathrm{~J}^{\mathrm{T}}$ is different from related type strains; for example, strain MUSC $93 \mathrm{~J}^{\mathrm{T}}$ contain two aminolipids (Figure S3A), while Streptomyces malachitofuscus JCM $4493^{\mathrm{T}}$ only contain one aminolipids (Figure S3B).

The chemotaxonomic analyses also demonstrated that the cell wall of strain MUSC $93 \mathrm{~J}^{\mathrm{T}}$ is of cell-wall type $\mathrm{I}$ as it contains LL-diaminopimelic (Lechevalier and Lechevalier, 1970). Many other species of the genus Streptomyces were also found to have LL-diaminopimelic (Lee et al., 2005, 2014d; Xu et al., 2009; Hu et al., 2012; Ser et al., 2015b,d). The predominant menaquinones of strain MUSC $93 \mathrm{~J}^{\mathrm{T}}$ were identified as MK-9 $\left(\mathrm{H}_{8}\right)$ $(42 \%)$ and MK-9 $\left(\mathrm{H}_{6}\right)(35 \%)$. This finding is in agreement with the report of the study conducted by Kim et al. (2003), in which the predominant menaquinones of Streptomyces are MK-9 $\left(\mathrm{H}_{8}\right)$ and MK-9( $\left.\mathrm{H}_{6}\right)$. The cell wall peptidoglycan was determined to contain LL-diaminopimelic acid. The whole cell sugars were found to be glucose, mannose, and ribose. The $\mathrm{G}+\mathrm{C}$ content of strain MUSC $93 \mathrm{~J}^{\mathrm{T}}$ was found to be $69.9 \mathrm{~mol} \%$; this is within the range of $67.0-78.0 \mathrm{~mol} \%$ described for species of the genus Streptomyces (Kim et al., 2003).

\section{Phenotypic Analyses of Strain MUSC 93J}

Strain MUSC 93 $\mathrm{J}^{\mathrm{T}}$ exhibited good growth on ISP 2 agar, ISP 6 agar, and Streptomyces agar after 7 days at $28^{\circ} \mathrm{C}$, moderate growth on starch casein agar, weak growth on nutrient agar, and no growth on actinomycetes isolation agar, ISP 3, ISP 4, ISP 5 , and ISP 7 agar. The 15-day-old culture of strain MUSC 93J ${ }^{\mathrm{T}}$ formed light yellow aerial and vivid yellow substrate mycelium on ISP 2 agar (Table 2). These morphological characteristics are consistent with grouping of the strain to the genus Streptomyces (Williams, 1989). The $\mathrm{NaCl}$ tolerance, temperature ranges, and $\mathrm{pH}$ for growth of strain MUSC $93 \mathrm{~J}^{\mathrm{T}}$ occurred at $0-4 \%$ (optimum $0-2 \%$ ), $24-36^{\circ} \mathrm{C}$ (optimum 0-2\%), and $\mathrm{pH} 6.0-7.0$ (optimum pH 6.0), respectively. The cells of MUSC 93 ${ }^{\mathrm{T}}$ were positive for catalase and haemolytic activities. Hydrolysis of soluble starch, casein and tributyrin (lipase) were positive; but negative for hydrolysis of chitin, carboxymethylcellulose, and xylan. Based on a range of phenotypic properties, strain MUSC $93 \mathrm{~J}^{\mathrm{T}}$ can be differentiated from closely related members of the genus Streptomyces (Table 2). In chemical sensitivity assays, cells are resistant to $1 \%$ sodium lactate, $\mathrm{D}$-serine, rifamycin $\mathrm{RV}$, minocycline, lincomycin, niaproof 4, tetrazolium violet, tetrazolium blue, nalidixic acid, potassium tellurite, aztreonam, sodium butyrate, and sodium bromate.

According to the outcomes of genomic, phylogenetic, chemotaxonomic and phenotypic analyses, strain MUSC $93 \mathrm{~J}^{\mathrm{T}}$ merits assignment to a novel species in the genus Streptomyces, for which the name Streptomyces colonosanans sp. nov. is proposed.

\section{Antioxidant Activity of Strain MUSC 93J Extract}

Oxygen free radicals, also known as reactive oxygen species (ROS) are products of a normal cellular metabolism process in an organism (Valko et al., 2006). Oxidative stress occurs when there is an overproduction free radicals and deficiency of antioxidants, resulting in the accumulation of free radicals (Valko et al., 2006; Reuter et al., 2010). This condition may cause damage to DNA, proteins, and lipids which has been associated with the development of age-related diseases such as cancer, arthritis, and neurodegenerative disorders in living organisms (Valko et al., 2006; Tan et al., 2015). For that reason, antioxidants are required as they may play an important role in preventing the deleterious effects of free radicals and thus they are regard as potential bioactive agents against cancers in human (Kawanishi 
TABLE 2 | Differentiation characteristics of strain MUSC 93J $\mathrm{J}^{\mathrm{T}}$ and type strains of phylogenetically closely related species of the genus Streptomyces.

\begin{tabular}{|c|c|c|c|c|}
\hline Characteristic & 1 & 2 & 3 & 4 \\
\hline \multicolumn{5}{|c|}{ MORPHOLOGY (ON ISP 2): } \\
\hline $\begin{array}{l}\text { Color of aerial } \\
\text { mycelium }\end{array}$ & $\begin{array}{l}\text { Light } \\
\text { yellow }\end{array}$ & $\begin{array}{l}\text { Pale greenish } \\
\text { yellow }\end{array}$ & $\begin{array}{l}\text { Yellowish } \\
\text { white }\end{array}$ & Light yellow \\
\hline $\begin{array}{l}\text { Color of substrate } \\
\text { mycelium }\end{array}$ & $\begin{array}{l}\text { Vivid } \\
\text { yellow }\end{array}$ & $\begin{array}{l}\text { Vivid greenish } \\
\text { yellow }\end{array}$ & $\begin{array}{l}\text { Yellowish } \\
\text { gray }\end{array}$ & $\begin{array}{c}\text { Brilliant Greenish } \\
\text { yellow }\end{array}$ \\
\hline \multicolumn{5}{|l|}{ GROWTH AT } \\
\hline $28^{\circ} \mathrm{C}$ & + & $(+)$ & $(+)$ & + \\
\hline $36^{\circ} \mathrm{C}$ & $(+)$ & + & + & + \\
\hline $\mathrm{pH} 6$ & + & $(+)$ & $(+)$ & $(+)$ \\
\hline $2 \% \mathrm{NaCl}$ & + & $(+)$ & + & $(+)$ \\
\hline Catalase & + & + & + & + \\
\hline Hemolytic & + & - & - & - \\
\hline \multicolumn{5}{|l|}{ HYDROLYSIS OF } \\
\hline Casein (protease) & + & - & - & + \\
\hline Tributyrin (lipase) & + & - & + & + \\
\hline Starch (amylolytic) & + & + & + & + \\
\hline $\begin{array}{l}\text { Carboxymethylcellulose } \\
\text { (cellulase) }\end{array}$ & - & + & + & + \\
\hline Xylan (xylanase) & - & - & + & - \\
\hline \multicolumn{5}{|c|}{ CARBON SOURCE UTILIZATION } \\
\hline D-maltose & - & + & + & + \\
\hline Sucrose & - & + & + & + \\
\hline D-turanose & - & + & + & + \\
\hline D-raffinose & + & - & + & - \\
\hline$\alpha$-D-lactose & - & + & + & + \\
\hline$\beta$-methyl-D-glucoside & - & + & - & + \\
\hline D-salicin & - & + & - & + \\
\hline $\begin{array}{l}\mathrm{N} \text {-acetyl-D- } \\
\text { glucosamine }\end{array}$ & - & + & + & + \\
\hline D-fructose & - & + & + & + \\
\hline L-rhamnose & - & + & - & + \\
\hline D-sorbitol & - & + & + & + \\
\hline myo-inositol & - & + & + & + \\
\hline Pectin & - & + & + & + \\
\hline Methyl pyruvate & - & + & + & + \\
\hline $\begin{array}{l}\text { D-lactic acid methyl } \\
\text { ester }\end{array}$ & - & + & + & + \\
\hline Citric acid & - & + & + & + \\
\hline$\alpha$-keto-glutaric acid & - & + & + & + \\
\hline D-malic acid & - & + & + & + \\
\hline L-malic acid & - & + & + & + \\
\hline Bromo-succinic acid & - & + & + & + \\
\hline Propionic acid & - & + & + & + \\
\hline Acetic acid & - & + & + & + \\
\hline Formic acid & - & + & + & + \\
\hline
\end{tabular}

Strains: 1, Streptomyces colonosanans MUSC 93J ; 2, Streptomyces malachitofuscus JCM 4493 ${ }^{T}$; 3, Streptomyces misionensis NBRC $13063^{T} ; 4$, Streptomyces phaeoluteichromatogenes DSM $41898^{T}$. All data were obtained concurrently in this study. +, Positive; -, negative; (+), weak.

All strains are positive for utilization of Dextrin, D-trehalose, D-cellobiose, Gentiobiose, $\alpha$-D-glucose, D-mannose, D-galactose, glycerol, D-glucose-6-PO4, D-fructose-6-PO4, Gelatin, D-galacturonic acid, L-galactonic acid lactone, D-gluconic acid, D-glucuronic acid, Glucuronamide, p-hydroxy-phenylacetic acid, L-lactic acid, Tween 40, $\gamma$-aminobutyric acid, $\alpha$-hydroxy-butyric acid, $\beta$-hydroxy-D,L-butyric acid, $\alpha$-keto-butyric acid, and acetoacetic acid. All strains are negative for assimilation of 3-methyl glucose. et al., 2005; Reuter et al., 2010; Ser et al., 2016b). For example, a trial conducted by Blot et al. (1993) in China suggested that combination of antioxidants of beta carotene, vitamin $\mathrm{E}$, and selenium may decrease the risk of gastric cancer. Besides, several studies and meta-analysis of the epidemiological literature have shown that increased intake of lycopene, a potent antioxidant present in tomatoes, is associated with reduced risk of prostate cancer (Gann et al., 1999; Giovannucci et al., 2002; Etminan et al., 2004) and gastric cancer (Yang et al., 2013).

In the early 1980s, the scientific community started to focus on the exploration of microbial antioxidants. Since then, researchers have discovered and characterized a variety of antioxidant compounds from microorganisms in hope to be developed into novel therapeutic agents (Hall, 2001). Due to the pathophysiological complexity of the human diseases, the bioprospecting activities in search for more effective and specific antioxidants from natural resources is still required. In this context, Streptomyces bacteria emerges as one of the good sources of natural compounds since they are prolific producers of bioactive secondary metabolites. Furthermore, several studies have reported the detection of compounds with antioxidant property extracted from Streptomyces spp., for instance, thiazostatin A and thiazostatin B (Shindo et al., 1989), diphenazithionin (Hosoya et al., 1996), dihydroherbimycin A (Chang and Kim, 2007) as well as 5(2,4-dimethylbenzyl)pyrrolidin-2-one (Saurav and Kannabiran, 2012).

The present study showed that MUSC 93 ${ }^{\mathrm{T}}$ merits assignment to a novel species in the genus Streptomyces based on the polyphasic approach analyses. Since the strain MUSC $93 \mathrm{~J}^{\mathrm{T}}$ is a novel Streptomyces species, it would be interesting to investigate the antioxidant potential of this strain. Hence, the strain was further examined for its antioxidant potential using ABTS, metal chelating, and SOD activity assays. According to the results of antioxidant assays, it can be observed that MUSC 93 $\mathrm{J}^{\mathrm{T}}$ extract exhibited significant free radical scavenging activity (Table 3). In ABTS assay, ABTS radical cation was produced by the reaction between a strong oxidizing agent potassium persulfate with ABTS salt and the ability of antioxidant to scavenge the ABTS radical generated in the aqueous phase will be measured (Shalaby and Shanab, 2013). The results showed that MUSC 93J ${ }^{\mathrm{T}}$ extract was capable of scavenging $11.80 \pm 3.75 \%$ of ABTS radicals at the highest test concentration of $2 \mathrm{mg} / \mathrm{mL}$. Besides, MUSC 93 ${ }^{\mathrm{T}}$ extract exhibited metal chelating activity of $50.06 \pm 1.95 \%$ at $2 \mathrm{mg} / \mathrm{mL}$ concentration. This indicated the antioxidative potential of MUSC $93 \mathrm{~J}^{\mathrm{T}}$ extract through prevention of transition metals from enhancing the production of ROS (Ser et al., 2016b). In addition, the SOD assay also confirmed the antioxidant potential of MUSC 93 ${ }^{\mathrm{T}}$ extract. In SOD assay, the superoxide anion scavenging activity of this extract was determined by the 2-(4-iodophenyl)-3-(4-nitrophenyl)-5(2,4-disulfophenyl)-2H-tetrazolium, monosodium salt (WST) reduction method. The superoxide anion radical produced from hypoxanthine-xanthine oxidase reaction reduces WST-1 to produce yellow formazan (Dudonné et al., 2009; Tan et al., 2015). MUSC 93J ${ }^{\mathrm{T}}$ extract exhibited superoxide dismutase (SOD)-like activity which may subsequently prevent the formation of yellow 
TABLE 3 | Radical scavenging activity of MUSC $93 \mathrm{~J}^{\top}$ evaluated using ABTS, metal chelating, and SOD assays.

\begin{tabular}{lcc}
\hline Antioxidants assays & $\begin{array}{c}\text { Concentration of } \mathbf{M U S C} \\
\mathbf{9 3 \mathbf { J } ^ { \top }} \text { extract }(\mathbf{m g} \mathbf{m L})\end{array}$ & $\begin{array}{c}\text { Mean } \pm \text { standard } \\
\text { error }(\%)\end{array}$ \\
\hline ABTS & 0.25 & $5.65 \pm 2.56$ \\
& 0.50 & $1.35 \pm 1.76$ \\
1.00 & $4.60 \pm 3.24$ \\
& 2.00 & $11.80 \pm 3.75$ \\
\hline Metal chelating & 0.25 & $7.86 \pm 2.87$ \\
& 0.50 & $18.10 \pm 2.05$ \\
& 1.00 & $33.02 \pm 1.07$ \\
& 2.00 & $50.06 \pm 1.95$ \\
\hline SOD & 0.25 & $36.02 \pm 3.89$ \\
& 0.50 & $51.55 \pm 3.54$ \\
& 1.00 & $70.29 \pm 2.76$ \\
& 2.00 & $83.32 \pm 2.62$ \\
\hline
\end{tabular}

WST- 1 formazan. The SOD-like activity of this extract was 83.32 $\pm 2.62 \%$ at the highest tested concentration of $2 \mathrm{mg} / \mathrm{mL}$. All of these assays revealed significant antioxidant potential of MUSC $93 \mathrm{~J}^{\mathrm{T}}$ extract and thus suggested the presence of antioxidant(s) in it.

\section{Cytotoxic Activity of Strain MUSC 93 $\mathbf{J}^{\top}$ Extract}

In present study, cytotoxic potential of MUSC $93 \mathrm{~J}^{\mathrm{T}}$ extract was examined on human colon cancer cell lines namely HCT-116, HT-29, Caco-2, and SW480 by using the MTT assay. MTT assay is a tetrazolium-based colorimetric assay which operates by measuring the mitochondrial activity in living cells only. The activity of mitochondrial dehydrogenase enzyme of viable cells will transform the MTT tetrazolium salt (yellow) to MTT formazan crystal (purple) (Gerlier and Thomasset, 1986; Ser et al., 2015a; Tan et al., 2015). The use of different type of human colon cancer cell lines with different molecular characteristics as the panels for this experimentation is to assess varying efficacy of cytotoxic activity toward different genetic makeup of cancer cell lines (Tan et al., 2015). The tested results of MUSC 93J ${ }^{\mathrm{T}}$ extract against tested colon cancer cell lines were shown in (Figure 3).

The results revealed that MUSC $93 \mathrm{~J}^{\mathrm{T}}$ extract showed varying levels of cytotoxicity against HCT-116, HT-29, Caco-2, and SW480. It was found that the extract exhibited highest cytotoxic effect on SW480 with cell viability recorded at $63.6 \pm 3.0 \%$ when tested with highest concentration of $400 \mu \mathrm{g} / \mathrm{mL}$, followed by HCT-116 with cell viability $84.3 \pm 11.5 \%$ (at concentration $400 \mu \mathrm{g} / \mathrm{mL}$ ), then Caco-2 with cell viability $87.5 \pm 5.3 \%$ (at concentration $400 \mu \mathrm{g} / \mathrm{mL}$ ), and lastly the lowest cytotoxic effect on HT-29 with cell viability $88.4 \pm 4.4 \%$ (at concentration $400 \mu \mathrm{g} / \mathrm{mL}$; Figure 3). Furthermore, it can be observed that there was a dose dependent effect when the extract was tested against SW480 cells. SW480 cells were significantly inhibited $(p<0.05)$ by increased concentration of the extract. As for the human normal colon CCD-18Co cells, no significant cytotoxic effect was exerted by MUSC 93J ${ }^{\mathrm{T}}$ extract against these cells (Figure 3). Overall, the results suggested that MUSC $93 \mathrm{~J}^{\mathrm{T}}$ extract is more cytotoxic toward the colon cancer cells lines than the normal colon cells with particularly stronger cytotoxic activity against colon cancer cell line SW480.

\section{GC-MS Analysis of Strain MUSC 93J Extract}

GC-MS analysis was conducted to aid in chemical profiling and to identify compounds that present in the extract. The results of GC-MS analysis revealed that strain MUSC $93 \mathrm{~J}^{\mathrm{T}}$ extract contains nine compounds (Table 4): 2(5H)-Furanone (1), 1-Nonanol (2), Phenol, 2,4-bis (1,1-dimethylethyl)(3), Benzoic acid, 4-ethoxy-, ethyl ester (4), Pentanoic acid, 2,2,4-trimethyl-3-carboxyisopropyl, isobutyl ester (5), Pyrrolo[1,2-a]pyrazine-1,4-dione, hexahydro- (6), Pyrrolo[1,2a]pyrazine-1,4-dione, hexahydro-3-(2-methylpropyl)- (7), Pyrrolo[1,2-a]pyrazine-1,4-dione, hexahydro-3-(phenylmethyl)(8), 1,2-Benzenedicarboxylic acid, mono(2-ethylhexyl) ester (9) with chemical structures as shown in Figure 4. From this analysis, butenolides, fatty alcohol, phenolic, benzoic acid esters, hydrocarbon, pyrrolopyrazine, and dicarboxylic acid ester were the main classes of compounds present in strain MUSC $93 \mathrm{~J}^{\mathrm{T}}$ extract.

Pyrrolopyrazines are capable of exerting a variety of bioactivities such as antioxidant, antitumor, anti-angiogenesis, and antimicrobial (Ser et al., 2015a,b). According to the GCMS analysis, three pyrrolopyrazine compounds were detected in the MUSC $93 \mathrm{~J}^{\mathrm{T}}$ extract, including Pyrrolo[1,2-a]pyrazine1,4-dione, hexahydro- (6), Pyrrolo[1,2-a]pyrazine-1,4-dione, hexahydro-3-(2-methylpropyl)- (7), and Pyrrolo[1,2-a]pyrazine1,4-dione, hexahydro-3-(phenylmethyl)- (8). In previous studies, pyrrolo[1,2-a]pyrazine-1,4-dione, hexahydro- (6) was reported to be present in Streptomyces mangrovisoli, a novel Streptomyces species isolated from mangrove forest in Malaysia by Ser et al. (2015b) and it was suggested that this compound may be responsible for the antioxidant activity of this species. In addition, Pyrrolo[1,2-a]pyrazine-1,4-dione, hexahydro- (6) was also found in Streptomyces pluripotens and Bacillus sp. with the capability to reduce oxidative damages by free radicals (Gopi et al., 2014; Ser et al., 2015a). Moreover, Pyrrolo[1,2a]pyrazine-1,4-dione, hexahydro-3-(2-methylpropyl)- (7) was detected in Streptomyces sp. VITMK1 isolated from India mangrove soil by Manimaran et al. (2015). Mithun and Rao (2012) also reported the detection of Pyrrolo[1,2-a]pyrazine-1,4dione, hexahydro-3-(2-methylpropyl)- (7) in Micrococcus luteus with promising anticancer activity on HCT15. Also, all three pyrrolopyrazine compounds: Pyrrolo[1,2-a]pyrazine-1,4-dione, hexahydro- (6), Pyrrolo[1,2-a]pyrazine-1,4-dione, hexahydro3-(2-methylpropyl)- (7), and Pyrrolo[1,2-a]pyrazine-1,4-dione, hexahydro-3-(phenylmethyl)- (8) were detected in Streptomyces sp. MUM 256 isolated from mangrove forest in Malaysia by Tan et al. (2015) which exhibited antioxidant and anticancer activities that could be due to the presence of these pyrrolopyrazines. 

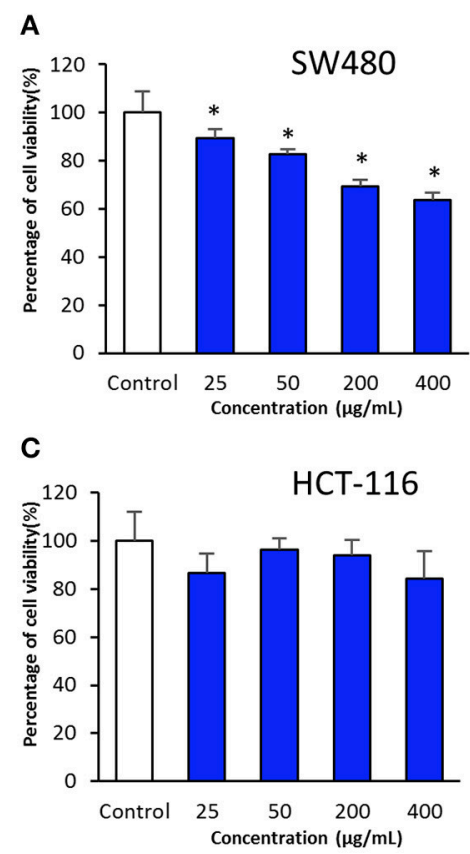

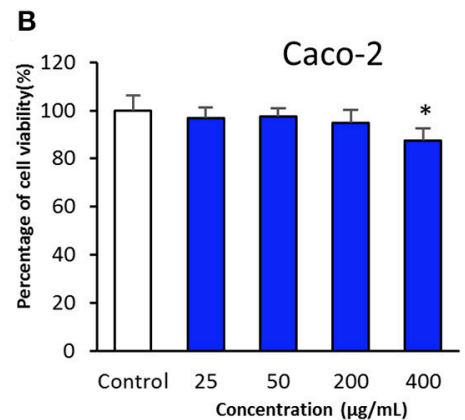

D

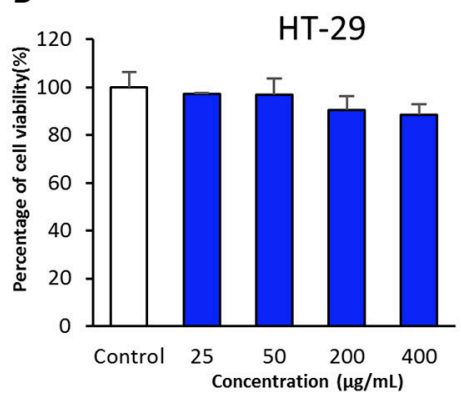

E

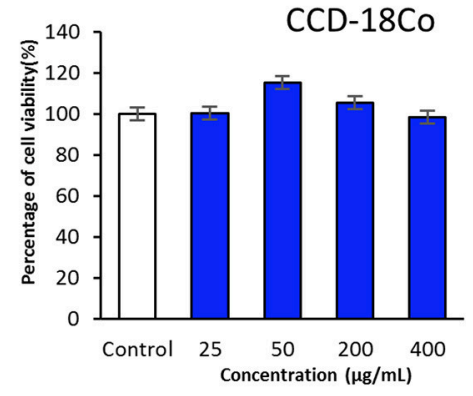

FIGURE 3 | Cytotoxic activity of MUSC $\mathbf{9 3} \mathbf{J}^{\mathbf{T}}$ extract against human colon cancer and normal cell lines. The measurement of cell viability was done using MTT assay. The graphs show cytotoxicity effect of MUSC 93J $J^{\top}$ extract against (A) SW480, (B) Caco-2, (C) HCT-116, (D) HT-29, and (E) CCD-18Co. All data are expressed as mean \pm standard deviation and significance level are set as 0.05 . Symbol $\left(^{*}\right)$ indicates $p<0.05$ significant difference between the cells treated with MUSC 93JT extract and control (without MUSC 93JT extract).

TABLE 4 | Compounds identified from MUSC 93J' extract using GC-MS.

\begin{tabular}{|c|c|c|c|c|c|c|}
\hline No. & $\begin{array}{l}\text { Retention } \\
\text { time (min) }\end{array}$ & Compound & Class & $\begin{array}{l}\text { Molecular } \\
\text { formula }\end{array}$ & $\begin{array}{c}\text { Molecular } \\
\text { weight (MW) }\end{array}$ & Quality (\%) \\
\hline 1 & 13.787 & 2(5H)-Furanone & Butenolides & $\mathrm{C}_{4} \mathrm{H}_{4} \mathrm{O}_{2}$ & 84 & 83 \\
\hline 2 & 27.325 & 1-Nonanol & Fatty alcohol & $\mathrm{C}_{9} \mathrm{H}_{20} \mathrm{O}$ & 144 & 83 \\
\hline 3 & 44.457 & Phenol, 2,4-bis(1,1-dimethylethyl)- & Phenolic compound & $\mathrm{C}_{14} \mathrm{H}_{22} \mathrm{O}$ & 206 & 93 \\
\hline 4 & 44.892 & Benzoic acid, 4-ethoxy-, ethyl ester & Benzoic acid esters & $\mathrm{C}_{11} \mathrm{H}_{14} \mathrm{O}_{3}$ & 194 & 91 \\
\hline 5 & 47.758 & Pentanoic acid, 2,2,4-trimethyl-3-carboxyisopropyl, isobutyl ester & Hydrocarbon & $\mathrm{C}_{16} \mathrm{H}_{30} \mathrm{O}_{4}$ & 286 & 78 \\
\hline 6 & 53.165 & Pyrrolo[1,2-a]pyrazine-1,4-dione, hexahydro- & Pyrrolopyrazine & $\mathrm{C}_{7} \mathrm{H}_{10} \mathrm{~N}_{2} \mathrm{O}_{2}$ & 154 & 96 \\
\hline 7 & 59.076 & Pyrrolo[1,2-a]pyrazine-1,4-dione, hexahydro-3-(2-methylpropyl)- & Pyrrolopyrazine & $\mathrm{C}_{11} \mathrm{H}_{18} \mathrm{~N}_{2} \mathrm{O}_{2}$ & 210 & 83 \\
\hline 8 & 72.031 & Pyrrolo[1,2-a]pyrazine-1,4-dione, hexahydro-3-(phenylmethyl)- & Pyrrolopyrazine & $\mathrm{C}_{14} \mathrm{H}_{16} \mathrm{~N}_{2} \mathrm{O}_{2}$ & 244 & 80 \\
\hline 9 & 76.883 & 1,2-Benzenedicarboxylic acid, mono(2-ethylhexyl) ester & Dicarboxylic acid ester & $\mathrm{C}_{16} \mathrm{H}_{22} \mathrm{O}_{4}$ & 278 & 87 \\
\hline
\end{tabular}

Hence, the antioxidant and cytotoxic activities exhibited by MUSC 93J ${ }^{\mathrm{T}}$ extract could be mainly due to the presence of these pyrrolopyrazine compounds.

Besides, phenolic compounds have been regard as important antioxidant agents responsible in scavenging ROS (Narendhran et al., 2014). Phenol, 2,4-bis(1,1-dimethylethyl)- (3) was the phenolic compound detected in strain MUSC $93 \mathrm{~J}^{\mathrm{T}}$ extract. Some of the recent studies have demonstrated the presence of phenol, 2,4-bis(1,1-dimethylethyl)- in Streptomyces bacteria through GC-MS analysis. For instance, Narendhran et al. (2014) successfully detected phenol, 2,4-bis(1,1-dimethylethyl)in Streptomyces cavouresis KUV39 isolated from vermicompost samples collected in India. The study also presented that this compound could be responsible for the antioxidant and cytotoxic properties of Streptomyces cavouresis KUV39. Besides, phenol, 2,4-bis(1,1-dimethylethyl)- was also detected in Streptomyces sp. MUM256 with potential antioxidant activity in the study conducted by Tan et al. (2015). A recently discovered novel Streptomyces antioxidans by Ser et al. (2016c) reported the detection of phenol, 2,4-bis(1,1-dimethylethyl)- was detected in the extract, which may had contributed to the strain's free radical scavenging activities.

The compound 1,2-Benzenedicarboxylic acid, mono(2ethylhexyl) ester (9) detected in MUSC 93 $\mathrm{J}^{\mathrm{T}}$ extract has been previously reported to possess potential antibacterial, antifungal, and cytotoxic activities (Saxena et al., 2015; Tan et al., 2015). 


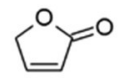

(1)

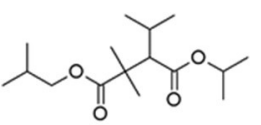

(5)

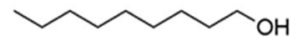

(2)

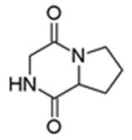

(6)

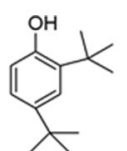

(3)

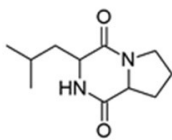

(7)

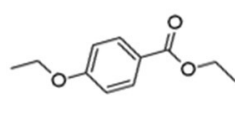

(4)

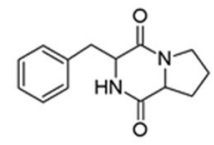

(8)

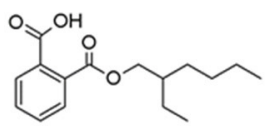

(9)

FIGURE 4 | Chemical structures of constituents detected in MUSC $93 \mathbf{J}^{\top}$ extract.

This compound was also detected in other Streptomyces sp., with cytotoxic activity against several cancer cell lines such as liver cancer cell line HepG2 and breast cancer cell line MCF7 (Krishnan et al., 2014).

Lastly, other detected compounds in MUSC 93 $\mathrm{J}^{\mathrm{T}}$ including 2(5H)-Furanone (1), 1-Nonanol (2), Benzoic acid, 4-ethoxy-, ethyl ester (4), and Pentanoic acid, 2,2,4-trimethyl-3carboxyisopropyl, isobutyl ester (5) were also previously found to be present in microbes. For instance, 2(5H)-Furanone was detected in Lactobacillus helveticus (Ndagijimana et al., 2006), 1-Nonanol was detected in Streptomyces albidoflavus (Sunesson et al., 1997), Benzoic acid, 4-ethoxy-, ethyl ester was detected in Bacillus sp. (Mishra and Thakur, 2016), and Pentanoic acid, 2,2,4-trimethyl-3-carboxyisopropyl, isobutyl ester was detected in Aspergillus carbonarius ITEM 5010 (Sinha et al., 2015).

Overall, most of the chemical compounds identified by GCMS are well-known for their antioxidant and anticancer activities. Therefore, we propose that these compounds, either alone or in combination, might be the main contributing factors for the antioxidant and cytotoxic properties present in MUSC $93 \mathrm{~J}^{\mathrm{T}}$ extract.

\section{Description of Streptomyces colonosanans sp. nov.}

Streptomyces colonosanans (co.lo.no.sa'nans. Gr. n. kolon, intestine, colon; L. part. adj. sanans, healing; N.L. part. adj. colonosanans, colon-healing).

Cells stain Gram-positive, forming light yellow aerial and vivid yellow substrate mycelium on ISP 2 agar. The colors of the aerial and substrate mycelium are media-dependent (Table S1). Cells grow well on ISP 2 agar, ISP 6 agar, and Streptomyces agar after 7 days at $28^{\circ} \mathrm{C}$, cells grow moderately on starch casein agar, and cells grow weakly on nutrient agar and did not grow on actinomycetes isolation agar, ISP 3, ISP 4, ISP 5, and ISP 7 agar. Cells grow at $0-4 \% \mathrm{NaCl}$ tolerance (optimum $0-2 \%$ ), $24-$ $36^{\circ} \mathrm{C}$ (optimum $28-32^{\circ} \mathrm{C}$ ), at $\mathrm{pH}$ 6.0-7.0 (optimum $\mathrm{pH} 6.0$ ). Cells are positive for catalase and hemolytic activities. Hydrolysis of soluble starch, casein and tributyrin (lipase) are positive; but negative for hydrolysis of chitin carboxymethylcellulose and xylan.

The following compounds are utilized as sole carbon sources: $\alpha$-D-glucose, $\alpha$-hydroxy-butyric acid, $\beta$-hydroxyl-D,L-butyric acid, D-cellobiose, dextrin, D-fructose-6-phosphate, L-fucose, D-galactose, D-galacturonic acid, D-glucose-6-phosphate, Dgluconic acid, D-glucuronic acid, D-mannose, D-melibiose, D-raffinose, D-trehalose, gelatin, gentiobiose, glucuronamide, glycerol, L-galactonic acid lactone, L-lactic acid, p-hydroxyphenylacetic acid, Tween 40, $\gamma$-amino-butyric acid, acetoacetic acid, and $\alpha$-keto-butyric acid. The following compounds are not utilized as sole carbon sources: acetic acid, $\alpha-\mathrm{D}$ lactose, $\alpha$-keto-glutaric acid, $\beta$-methyl-D-glucoside, bromosuccinic acid, citric acid, D-arabitol, D-aspartic acid, Dfructose, D-fucose, D-lactic acid methyl ester, D-malic acid, D-maltose, D-mannitol, D-saccharic acid, D-salicin, D-serine, D-sorbitol, D-turanose, formic acid, glycyl-L-proline, inosine, L-malic acid, L-rhamnose, methyl pyruvate, mucic acid, $\mathrm{N}$ acetyl- $\beta$-D-mannosamine, $\mathrm{N}$-acetyl-D-galactosamine, $\mathrm{N}$-acetyl$\mathrm{D}$-glucosamine, $\mathrm{N}$-acetyl-neuraminic acid, pectin, propionic acid, quinic acid, stachyose, sucrose, myo-inositol, and 3methyl glucose. The following compounds are not utilized as sole nitrogen sources: L-alanine, L-arginine, L-aspartic acid, L-glutamic acid, L-histidine, L-pyroglutamic acid, and Lserine. 
TABLE 5 | General features of Streptomyces colonosanans MUSC 93J genome.

Streptomyces colonosanans MUSC 93J $\mathbf{J}^{\top}$

\begin{tabular}{lc}
\hline Genome size (bp) & $7,015,076$ \\
Contigs & 166 \\
Contigs $N_{50}(\mathrm{bp})$ & 99,963 \\
G + C content \% & 69.90 \\
Protein coding genes & 5,859 \\
tRNA & 66 \\
rRNA & $3(5 S), 1(16 S), 1(23 S)$ \\
\hline
\end{tabular}

The cell wall peptidoglycan contains LL-diaminopimelic acid. The predominant menaquinones were identified as MK-9 $\left(\mathrm{H}_{8}\right)$ and MK-9 $\left(\mathrm{H}_{6}\right)$. The whole cell sugars are glucose, mannose and ribose. The polar lipids consist of aminolipid, diphosphatidylglycerol, lipid, phospholipid, phosphatidylinositol, phosphatidylethanolamine, and phosphoglycolipid. The predominant cellular fatty acids (>10.0\%) are anteiso- $\mathrm{C}_{15: 0}, \mathrm{C}_{16: 0}$, and iso- $\mathrm{C}_{16: 0}$.

The type strain is MUSC $93 \mathrm{~J}^{\mathrm{T}}\left(=\mathrm{DSM} 102042^{\mathrm{T}}=\right.$ MCCC $\left.1 \mathrm{~K}_{02} 2298^{\mathrm{T}}\right)$, isolated from mangrove soil collected from mangrove forest located in Kuching, state of Sarawak, Malaysia. The 16S rRNA gene sequence of strain MUSC 93 $\mathrm{J}^{\mathrm{T}}$ has been deposited in GenBank/EMBL/DDBJ under the accession number KP998434. The genome of MUSC $93 \mathrm{~J}^{\mathrm{T}}$ consists of 7,015,076 bp with average coverage of 53.0 -fold and the $\mathrm{G}+\mathrm{C}$ content of the genomic DNA of the type strain is $69.90 \mathrm{~mol} \%$. The whole project of MUSC $93 \mathrm{~J}^{\mathrm{T}}$ has been deposited at DDBJ/EMBL/GenBank under accession number MLYP00000000. A total of 5,859 coding genes was predicted and assigned to 402 subsystems, along with 66 tRNA and 5 RNA genes (Table 5). Based on RAST annotation, most of the genes were involved in amino acids and derivatives metabolism (9.18\%), followed by carbohydrates metabolism (6.21\%) and protein metabolism subsystems (4.91\%).

\section{CONCLUSION}

This study has revealed that strain MUSC $93 \mathrm{~J}^{\mathrm{T}}$ is a novel species of the genus Streptomyces, isolated from the soil of mangrove forest located in Kuching, Sarawak. The name Streptomyces colonosanans sp. nov. is proposed and the type

\section{REFERENCES}

Angiuoli, S. V., Gussman, A., Klimke, W., Cochrane, G., Field, D., Garrity, G. M., et al. (2008). Toward an online repository of Standard Operating Procedures (SOPs) for (meta) genomic annotation. OMICS 12, 137-141. doi: 10.1089/omi.2008.0017

Arumugam, M., Mitra, A., Pramanik, A., Saha, M., Gachhui, R., and Mukherjee, J. (2011). Streptomyces sundarbansensis sp. nov., an actinomycete that produces 2-allyloxyphenol. Int. J. Syst. Evol. Microbiol. 61, 2664-2669. doi: $10.1099 /$ ijs.0.028258-0

Ashton, E. C., and Macintosh, D. J. (2002). Preliminary assessment of the plant diversity and community ecology of the Sematan strain is MUSC $93 \mathrm{~J}^{\mathrm{T}}\left(=\mathrm{DSM} 102042^{\mathrm{T}}=\mathrm{MCCC} 1 \mathrm{~K} 02298^{\mathrm{T}}\right)$. This study revealed that the extract of strain MUSC $93 \mathrm{~J}^{\mathrm{T}}$ has significant antioxidant potential with radical scavenging activity up to $83.32 \pm 2.62 \%$ via SOD assay. Additionally, this strain exhibited cytotoxic activity against several human colon cancer cell lines, with highest cytotoxic effect on SW480 with cell viability of $63.6 \pm 3.0 \%$. Chemical analysis via GC-MS further confirms that the strain is capable of producing chemopreventive related metabolites. Hence, this study demonstrated the biopharmaceutical potential of novel strain Streptomyces colonosanans MUSC $93 \mathrm{~J}^{\mathrm{T}}$ with capability to produce bioactive compounds responsible for the antioxidant and cytotoxic activities. Strain MUSC $93 \mathrm{~J}^{\mathrm{T}}$ serves as a potentially high quality resource for drug discovery and further studies pertaining the development of chemo-preventive drugs from this strain are highly valuable.

\section{AUTHOR CONTRIBUTIONS}

The experiments, data analysis, and manuscript writing were performed by JL and HS, while AD, SS, SIB, TK, NM, K-GC, BG, and LL provided vital guidance, insight and technical support for the completion of the project. L-HL and BG founded the research project.

\section{ACKNOWLEDGMENTS}

This work was supported by MOSTI ScienceFund Grant (Project No. 06-02-10-SF0300) and External Industry Grants from Biotek Abadi Sdn Bhd (vote no. GBA-808138 and GBA-808813) awarded to L-HL, University of Malaya for High Impact Research Grant (UM-MOHE HIR Nature Microbiome Grant No. H-50001A000027 and No. A000001-50001) awarded to K-GC, and supported by a grant from "Research Center of the Female Scientific and Medical Colleges," Deanship of Scientific Research, King Saud University awarded to SIB. The authors are thankful to Professor Bernhard Schink for the support in the Latin etymology of the new species name.

\section{SUPPLEMENTARY MATERIAL}

The Supplementary Material for this article can be found online at: http://journal.frontiersin.org/article/10.3389/fmicb. 2017.00877/full\#supplementary-material mangrove forest, Sarawak, Malaysia. For. Ecol. Manage. 166, 111-129. doi: 10.1016/S0378-1127(01)00673-9

Atlas, R. M. (1993). Handbook of Microbiological Media, ed L. C. Parks (Boca Raton, FL: CRC Press).

Aziz, R. K., Bartels, D., Best, A. A., Dejongh, M., Disz, T., Edwards, R. A., et al. (2008). The RAST Server: rapid annotations using subsystems technology. BMC Genomics 9:75. doi: 10.1186/1471-2164-9-75

Azman, A.-S., Othman, I. S., Velu, S., Chan, K.-G., and Lee, L.-H. (2015). Mangrove rare actinobacteria: taxonomy, natural compound, and discovery of bioactivity. Front. Microbiol. 6:856. doi: 10.3389/fmicb.2015.00856

Blot, W. J., Li, J.-Y., Taylor, P. R., Guo, W., Dawsey, S., Wang, G.-Q., et al. (1993). Nutrition intervention trials in Linxian, China: supplementation with 
specific vitamin/mineral combinations, cancer incidence, and disease-specific mortality in the general population. J. Nat. Cancer Inst. 85, 1483-1491. doi: $10.1093 /$ jnci/85.18.1483

Burja, A. M., Banaigs, B., Abou-Mansour, E., Burgess, J. G., and Wright, P. C. (2001). Marine cyanobacteria-a prolific source of natural products. Tetrahedron 57, 9347-9377. doi: 10.1016/S0040-4020(01)00931-0

Carrillo, P., Mardaraz, C., Pitta-Alvarez, S., and Giulietti, A. (1996). Isolation and selection of biosurfactant-producing bacteria. World J. Microbiol. Biotechnol. 12, 82-84. doi: 10.1007/BF00327807

Cashion, P., Holder-Franklin, M., Mccully, J., and Franklin, M. (1977). A rapid method for the base ratio determination of bacterial DNA. Anal. Biochem. 81, 461-466. doi: 10.1016/0003-2697(77)90720-5

Cerny, G. (1978). Studies on the aminopeptidase test for the distinction of gramnegative from gram-positive bacteria. Euro. J. Appl. Microbiol. Biotechnol. 5, 113-122. doi: 10.1007/BF00498805

Chang, H. B., and Kim, J.-H. (2007). Antioxidant properties of dihydroherbimycin A from a newly isolated Streptomyces sp. Biotechnol. Lett. 29, 599-603. doi: 10.1007/s10529-006-9288-z

Chin, Y.-W., Balunas, M. J., Chai, H. B., and Kinghorn, A. D. (2006). Drug discovery from natural sources. AAPS J. 8, E239-E253. doi: 10.1007/BF02854894

De Ley, J., Cattoir, H., and Reynaerts, A. (1970). The quantitative measurement of DNA hybridization from renaturation rates. Euro. J. Biochem. 12, 133-142. doi: 10.1111/j.1432-1033.1970.tb00830.x

Dudonné, S., Vitrac, X., Coutiere, P., Woillez, M., and MeİĄRillon, J.-M. (2009). Comparative study of antioxidant properties and total phenolic content of 30 plant extracts of industrial interest using DPPH, ABTS, FRAP, SOD, and ORAC assays. J. Agric. Food Chem. 57, 1768-1774. doi: 10.1021/jf803011r

Etminan, M., Takkouche, B., and Caamaño-Isorna, F. (2004). The role of tomato products and lycopene in the prevention of prostate cancer: a metaanalysis of observational studies. Cancer Epidemiol. Biomarkers Prev. 13, 340-345.

Felsenstein, J. (1981). Evolutionary trees from DNA sequences: a maximum likelihood approach. J. Mol. Evol. 17, 368-376. doi: 10.1007/BF01734359

Felsenstein, J. (1985). Confidence limits on phylogenies: an approach using the bootstrap. Evolution 39, 783-791. doi: 10.2307/2408678

Gann, P. H., Ma, J., Giovannucci, E., Willett, W., Sacks, F. M., Hennekens, C. H., et al. (1999). Lower prostate cancer risk in men with elevated plasma lycopene levels. Cancer Res. 59, 1225-1230.

Gerlier, D., and Thomasset, N. (1986). Use of MTT colorimetric assay to measure cell activation. J. Immunol. Methods 94, 57-63. doi: 10.1016/0022-1759(86)90215-2

Giovannucci, E., Rimm, E. B., Liu, Y., Stampfer, M. J., and Willett, W. C. (2002). A prospective study of tomato products, lycopene, and prostate cancer risk. J. Nat. Cancer Inst. 94, 391-398. doi: 10.1093/jnci/94.5.391

Giri, C., Ochieng, E., Tieszen, L. L., Zhu, Z., Singh, A., Loveland, T., et al. (2011). Status and distribution of mangrove forests of the world using earth observation satellite data. Global Ecol. Biogeogr. 20, 154-159. doi: $10.1111 / j .1466-8238.2010 .00584 . x$

Gopi, M., Dhayanithi, N. B., Devi, K. N., and Kumar, T. T. A. (2014). Marine natural product, Pyrrolo [1,2-a] pyrazine-1,4-dione, hexahydro- $\left(\mathrm{C}_{7} \mathrm{H}_{10} \mathrm{~N}_{2} \mathrm{O}_{2}\right)$ of antioxidant properties from Bacillus species at Lakshadweep archipelago. J. Coast. Life Med. 2, 632-637. doi: 10.12980/JCLM.2.201414J40

Hall, C. (2001). "Sources of natural antioxidants: oilseeds, nuts, cereals, legumes, animal products and microbial sources," in Antioxidants Food, eds J. Pokorný, N. Yanishlieva, and M. Gordon (Cambridge: Woodhead Publishing Ltd.), 180-189. doi: 10.1201/9781439823057.ch9

Hong, K., Gao, A.-H., Xie, Q.-Y., Gao, H. G., Zhuang, L., Lin, H.-P., et al. (2009). Actinomycetes for marine drug discovery isolated from mangrove soils and plants in China. Mar. Drugs 7, 24-44. doi: 10.3390/md7010024

Hosoya, Y., Adachi, H., Nakamura, H., Nishimura, Y., Naganawa, H., Okami, Y., et al. (1996). The structure of diphenazithionin, a novel antioxidant from Streptomyces griseus ISP 5236. Tetrahedron Lett. 37, 9227-9228. doi: 10.1016/S0040-4039(96)02190-9

Hu, H., Lin, H.-P., Xie, Q., Li, L., Xie, X.-Q., and Hong, K. (2012). Streptomyces qinglanensis sp. nov., isolated from mangrove sediment. Int. J. Syst. Evol. Microbiol. 62, 596-600. doi: 10.1099/ijs.0.032201-0
Huss, V. A., Festl, H., and Schleifer, K. H. (1983). Studies on the spectrophotometric determination of DNA hybridization from renaturation rates. Syst. Appl. Microbiol. 4, 184-192. doi: 10.1016/S0723-2020(83)80048-4

Hyatt, D., Chen, G.-L., Locascio, P. F., Land, M. L., Larimer, F. W., and Hauser, L. J. (2010). Prodigal: prokaryotic gene recognition and translation initiation site identification. BMC Bioinformatics 11:119. doi: 10.1186/1471-2105-11-119

Karikas, G. (2010). Anticancer and chemopreventing natural products: some biochemical and therapeutic aspects. J. BUON 15, 627-638.

Kates, M. (1986). "Lipid extraction procedures," in Techniques of Lipidology (Amsterdam: Elsevier), 106-107.

Kato, S., Kawai, H., Kawasaki, T., Toda, Y., Urata, T., and Hayakawa, Y. (1989). Studies on free radical scavenging substances from microorganisms. I. Carazostatin, a new free radical scavenger produced by Streptomyces chromofuscus DC 118. J. Antibiot. 42, 1879-1881. doi: 10.7164/antibiotics. 42.1879

Kawanishi, S., Oikawa, S., and Murata, M. (2005). Evaluation for safety of antioxidant chemopreventive agents. Antioxid. Redox Signal. 7, 1728-1739. doi: 10.1089/ars.2005.7.1728

Kim, O.-S., Cho, Y.-J., Lee, K., Yoon, S.-H., Kim, M., Na, H., et al. (2012). Introducing EzTaxon-e: a prokaryotic 16S rRNA gene sequence database with phylotypes that represent uncultured species. Int. J. Syst. Evol. Microbiol. 62, 716-721. doi: 10.1099/ijs.0.038075-0

Kim, S. B., Lonsdale, J., Seong, C.-N., and Goodfellow, M. (2003). Streptacidiphilus gen. nov., acidophilic actinomycetes with wall chemotype I and emendation of the family Streptomycetaceae (Waksman and Henrici (1943) AL) emend. Rainey et al. 1997. Antonie van Leeuwenhoek 83, 107-116. doi: 10.1023/A:1023397724023

Kimura, M. (1980). A simple method for estimating evolutionary rates of base substitutions through comparative studies of nucleotide sequences. J. Mol. Evol. 16, 111-120. doi: 10.1007/BF01731581

Kinkel, L. L., Schlatter, D. C., Xiao, K., and Baines, A. D. (2014). Sympatric inhibition and niche differentiation suggest alternative coevolutionary trajectories among Streptomycetes. ISME J. 8, 249-256. doi: 10.1038/ismej.2013.175

Kino, T., Hatanaka, H., Miyata, S., Inamura, N., Nishiyama, M., Yajima, T., et al. (1987). FK-506, a novel immunosuppressant isolated from a Streptomyces. J. Antibiot. 40, 1256-1265. doi: 10.7164/antibiotics.40.1256

Krishnan, K., Mani, A., and Jasmine, S. (2014). Cytotoxic activity of bioactive compound 1, 2-benzene dicarboxylic acid, mono 2-ethylhexyl ester extracted from a marine derived Streptomyces sp. VITSJK8. Int. J. Mol. Cell. Med. 3, 246.

Küster, E., and Williams, S. (1964). Media for the isolation of streptomycetes: starch casein medium. Nature 202, 928-929. doi: 10.1038/202928a0

Lagesen, K., Hallin, P., Rødland, E. A., StÃęrfeldt, H.-H., Rognes, T., and Ussery, D. W. (2007). RNAmmer: consistent and rapid annotation of ribosomal RNA genes. Nucleic Acids Res. 35, 3100-3108. doi: 10.1093/nar/gkm160

Law, J. W.-F., Ser, H.-L., Khan, T. M., Chuah, L.-H., Pusparajah, P., Chan, K.-G., et al. (2017). The potential of Streptomyces as biocontrol agents against the rice blast fungus, Magnaporthe oryzae (Pyricularia oryzae). Front. Microbiol. 8:3. doi: $10.3389 /$ fmicb.2017.00003

Lechevalier, M. P., and Lechevalier, H. (1970). Chemical composition as a criterion in the classification of aerobic actinomycetes. Int. J. Syst. Evol. Microbiol. 20, 435-443. doi: 10.1099/00207713-20-4-435

Lee, J. Y., Lee, J. Y., Jung, H. W., and Hwang, B. K. (2005). Streptomyces koyangensis sp. nov., a novel actinomycete that produces 4-phenyl-3-butenoic acid. Int. J. Syst. Evol. Microbiol. 55, 257-262. doi: 10.1099/ijs.0.63168-0

Lee, L.-H., Azman, A.-S., Zainal, N., Eng, S.-K., Ab Mutalib, N.-S., Yin, W.-F., et al. (2014a). Microbacterium mangrovi sp. nov., an amylolytic actinobacterium isolated from mangrove forest soil. Int. J. Syst. Evol. Microbiol. 64, 3513-3519. doi: 10.1099/ijs.0.062414-0

Lee, L.-H., Azman, A.-S., Zainal, N., Eng, S.-K., Fang, C.-M., Hong, K., et al. (2014b). Novosphingobium malaysiense sp. nov. isolated from mangrove sediment. Int. J. Syst. Evol. Microbiol. 64, 1194-1201. doi: 10.1099/ijs.0.05 9014-0

Lee, L.-H., Cheah, Y.-K., Sidik, S. M., Ab Mutalib, N.-S., Tang, Y.-L., Lin, H.-P., et al. (2012). Molecular characterization of Antarctic actinobacteria and screening for antimicrobial metabolite production. World J. Microbiol. Biotechnol. 28, 2125-2137. doi: 10.1007/s11274-012-1018-1 
Lee, L.-H., Zainal, N., Azman, A.-S., Ab Mutalib, N.-S., Hong, K., and Chan, K.-G. (2014c). Mumia flava gen. nov., sp. nov., an actinobacterium of the family Nocardioidaceae. Int. J. Syst. Evol. Microbiol. 64, 1461-1467. doi: 10.1099/ijs.0.058701-0

Lee, L.-H., Zainal, N., Azman, A.-S., Eng, S.-K., Ab Mutalib, N.-S., Yin, W.F., et al. (2014d). Streptomyces pluripotens sp. nov., a bacteriocin-producing streptomycete that inhibits meticillin-resistant Staphylococcus aureus. Int. J. Syst. Evol. Microbiol. 64, 3297-3306. doi: 10.1099/ijs.0.065045-0

Lee, L.-H., Zainal, N., Azman, A.-S., Eng, S.-K., Goh, B.-H., Yin, W.-F., et al. (2014e). Diversity and antimicrobial activities of actinobacteria isolated from tropical mangrove sediments in Malaysia. Sci. World J. 2014:698178. doi: $10.1155 / 2014 / 698178$

Lowe, T. M., and Eddy, S. R. (1997). tRNAscan-SE: a program for improved detection of transfer RNA genes in genomic sequence. Nucleic Acids Res. 25, 955-964. doi: 10.1093/nar/25.5.0955

Macfaddin, J. E. (2000). Biochemical Tests for Identification of Medical Bacteria, eds. J. E. Macfaddin (Philadelphia, PA: Lippincott Williams \& Wilkins).

Mangamuri, U. K., Muvva, V., Poda, S., and Kamma, S. (2012). Isolation, Identification and molecular characterization of rare actinomycetes from mangrove ecosystem of nizampatnam. Malays. J. Microbiol. 8, 83-91. doi: $10.21161 / \mathrm{mjm} .03212$

Manimaran, M., Gopal, J. V., and Kannabiran, K. (2015). Antibacterial activity of Streptomyces sp. VITMK1 isolated from mangrove soil of Pichavaram, Tamil Nadu, India. Proc. Natl. Acad. Sci. India Sect. B Biol. Sci. 1-8. doi: 10.1007/ s40011-015-0619-5

Manivasagan, P., Venkatesan, J., Sivakumar, K., and Kim, S.-K. (2013). Production, characterization and antioxidant potential of protease from Streptomyces sp. MAB18 using poultry wastes. BioMed. Res. Int. 2013:496586. doi: 10.1155/2013/496586.

Mesbah, M., Premachandran, U., and Whitman, W. B. (1989). Precise measurement of the $\mathrm{G}+\mathrm{C}$ content of deoxyribonucleic acid by highperformance liquid chromatography. Int. J. Syst. Evol. Microbiol. 39, 159-167. doi: 10.1099/00207713-39-2-159

Miser-Salihoglu, E., Akaydin, G., Caliskan-Can, E., and Yardim-Akaydin, S. (2013). Evalution of antioxidant activity of various herbal folk medicines. Nutr. Food Sci. 3:222. doi: 10.4172/2155-9600.1000222

Mishra, M., and Thakur, I. S. (2016). 16S r-DNA based denaturing gradient gel electrophoresis method for evaluation of survival of lignin degrading bacteria Bacillus Sp. in soil microcosms. J. Chem. Biol. Phys. Sci. 6, 396.

Mithun, V. S. L., and Rao, C. S. V. (2012). Isolation and molecular characterization of anti-cancerous compound producing marine bacteria by using $16 \mathrm{~S}$ rRNA sequencing and GC-MS techniques. IJMER 2, 4510-4515.

Mo, C.-J., Shin-Ya, K., Furihata, K., Furihata, K., Shimazu, A., Hayakawa, Y., et al. (1990). Isolation and structural elucidation of antioxidative agents, antiostatins A1 to A4 and B2 to B5. J. Antibiot. 43, 1337-1340. doi: 10.7164/antibiotics.43.1337

Narendhran, S., Rajiv, P., Vanathi, P., and Sivaraj, R. (2014). Spectroscopic analysis of bioactive compounds from Streptomyces cavouresis kuv39: Evaluation of antioxidant and cytotoxicity activity. Int. J. Pharm. Pharm. Sci. 6, 319-322. Available online at: https://innovareacademics.in/journals/index.php/ijpps/ article/viewFile/2009/911

Ndagijimana, M., Vallicelli, M., Cocconcelli, P. S., Cappa, F., Patrignani, F., Lanciotti, R., et al. (2006). Two 2 [5H]-furanones as possible signaling molecules in Lactobacillus helveticus. Appl. Environ. Microbiol. 72, 6053-6061. doi: 10.1128/AEM.00363-06

Nobili, S., Lippi, D., Witort, E., Donnini, M., Bausi, L., Mini, E., et al. (2009). Natural compounds for cancer treatment and prevention. Pharmacol. Res. 59, 365-378. doi: 10.1016/j.phrs.2009.01.017

Rashad, F. M., Fathy, H. M., El-Zayat, A. S., and Elghonaimy, A. M. (2015). Isolation and characterization of multifunctional Streptomyces species with antimicrobial, nematicidal and phytohormone activities from marine environments in Egypt. Microbiol. Res. 175, 34-47. doi: 10.1016/j.micres.2015.03.002

Reuter, S., Gupta, S. C., Chaturvedi, M. M., and Aggarwal, B. B. (2010). Oxidative stress, inflammation, and cancer: how are they linked? Free Radic. Biol. Med. 49, 1603-1616. doi: 10.1016/j.freeradbiomed.2010.09.006

Saitou, N., and Nei, M. (1987). The neighbor-joining method: a new method for reconstructing phylogenetic trees. Mol. Biol. Evol. 4, 406-425.
Sasser, M. (1990). Identification of bacteria by gas chromatography of cellular fatty acids. MIDI Technical Note 101. (Newark, DE: Microbial ID Inc.). Available online at: http://www.microbialid.com/PDF/TechNote_101.pdf

Satheeja, S. V., and Jebakumar, S. R. (2011). Phylogenetic analysis and antimicrobial activities of Streptomyces isolates from mangrove sediment. J. Basic Microbiol. 51, 71-79. doi: 10.1002/jobm.201000107

Saurav, K., and Kannabiran, K. (2012). Cytotoxicity and antioxidant activity of 5-(2, 4-dimethylbenzyl) pyrrolidin-2-one extracted from marine Streptomyces VITSVK5 spp. Saudi J. Biol. Sci. 19, 81-86. doi: 10.1016/j.sjbs.2011.07.003

Saxena, S., Meshram, V., and Kapoor, N. (2015). Muscodor tigerii sp. nov.-Volatile antibiotic producing endophytic fungus from the Northeastern Himalayas. Ann. Microbiol. 65, 47-57. doi: 10.1007/s13213-014-0834-y

Schumann, P. (2011). 5- Peptidoglycan Structure. Method. Microbiol. 38, 101-129. doi: 10.1016/B978-0-12-387730-7.00005-X

Ser, H.-L., Ab Mutalib, N.-S., Yin, W.-F., Chan, K.-G., Goh, B.-H., and Lee, L.H. (2015a). Evaluation of antioxidative and cytotoxic activities of Streptomyces pluripotens MUSC 137 isolated from mangrove soil in Malaysia. Front. Microbiol. 6:1398. doi: 10.3389/fmicb.2015.01398

Ser, H.-L., Law, J. W.-F., Chaiyakunapruk, N., Jacob, S. A., Palanisamy, U. D., Chan, K.-G., et al. (2016a). Fermentation conditions that affect clavulanic acid production in Streptomyces clavuligerus: a systematic review. Front. Microbiol. 7:522. doi: $10.3389 /$ fmicb. 2016.00522

Ser, H.-L., Palanisamy, U. D., Yin, W.-F., Chan, K.-G., Goh, B.-H., and Lee, L.H. (2016b). Streptomyces malaysiense sp. nov.: a novel Malaysian mangrove soil actinobacterium with antioxidative activity and cytotoxic potential against human cancer cell lines. Sci. Rep. 6:24247. doi: 10.1038/srep24247

Ser, H.-L., Palanisamy, U. D., Yin, W.-F., Malek, S. N. A., Chan, K.-G., Goh, B.H., et al. (2015b). Presence of antioxidative agent, Pyrrolo [1, 2-a] pyrazine-1, 4-dione, hexahydro-in newly isolated Streptomyces mangrovisoli sp. nov. Front. Microbiol. 6:854. doi: 10.3389/fmicb.2015.00854

Ser, H.-L., Tan, L. T.-H., Palanisamy, U. D., Malek, S. N. A., Yin, W.-F., Chan, K.-G., et al. (2016c). Streptomyces antioxidans sp. nov., a novel mangrove soil actinobacterium with antioxidative and neuroprotective potentials. Front. Microbiol. 7:899. doi: 10.3389/fmicb.2016.00899

Ser, H.-L., Tan, W.-S., Ab Mutalib, N.-S., Cheng, H.-J., Yin, W.-F., Chan, K.G., et al. (2015c). Genome sequence of Streptomyces pluripotens MUSC 135 $\mathrm{T}$ exhibiting antibacterial and antioxidant activity. Mar. Gen. 24, 281-283. doi: 10.1016/j.margen.2015.09.010

Ser, H.-L., Tan, W.-S., Ab Mutalib, N.-S., Yin, W.-F., Chan, K.-G., Goh, B.-H., et al. (2016d). Draft genome sequence of mangrove-derived Streptomyces sp. MUSC 125 with antioxidant potential. Front. Microbiol. 7:1470. doi: $10.3389 /$ fmicb. 2016.01470

Ser, H.-L., Zainal, N., Palanisamy, U. D., Goh, B.-H., Yin, W.-F., Chan, K.G., et al. (2015d). Streptomyces gilvigriseus sp. nov., a novel actinobacterium isolated from mangrove forest soil. Antonie van Leeuwenhoek 107, 1369-1378. doi: 10.1007/s10482-015-0431-5

Shalaby, E. A., and Shanab, S. M. (2013). Comparison of DPPH and ABTS assays for determining antioxidant potential of water and methanol extracts of Spirulina platensis. Indian J. Geo-Mar. Sci. 42, 556-564. Available online at: http://nopr.niscair.res.in/bitstream/123456789/24794/1/ IJMS\%2042(5)\%20556-564.pdf

Sharma, S., and Shah, G. (2014). Isolation and screening of actinomycetes for bioactive compounds from the marine coast of South-Gujarat region. Int. J. Res. Sci. Innov. 1, 345-349. Available online at: http://www.rsisinternational. org/Issue7/345-349.pdf

Shindo, K., Takenaka, A., Noguchi, T., Hayakawa, Y., and Seto, H. (1989). Thiazostatin A and thiazostatin B. new antioxidants produced by Streptomyces tolurosus. J. Antibiot. 42, 1526-1529. doi: 10.7164/antibiotics.42.1526

Shin-ya, K., Furihata, K., Hayakawa, Y., Seto, H., Kato, Y., and Clardy, J. (1991). The structure of benthocyanin A. A new free radical scavenger of microbial origin. Tetrahedron Lett. 32, 943-946. doi: 10.1016/S0040-4039(00) 92126-9

Shinya, K., Furihata, K., Teshima, Y., Hayakawa, Y., and Seto, H. (1993). Benthocyanins B and C, new free radical scavengers from Streptomyces prunicolor. J. Org. Chem. 58, 4170-4172. doi: 10.1021/jo00067a069

Shirling, E. T., and Gottlieb, D. (1966). Methods for characterization of Streptomyces species. Int. J. Syst. Evol. Microbiol. 16, 313-340. doi: 10.1099/00207713-16-3-313 
Siegel, R. L., Miller, K. D., and Jemal, A. (2016). Cancer statistics, 2016. Cancer J. Clin. 66, 7-30. doi: 10.3322/caac.21332

Sinha, M., Sørensen, A., Ahamed, A., and Ahring, B. K. (2015). Production of hydrocarbons by Aspergillus carbonarius ITEM 5010. Fungal Biol. 119, 274-282. doi: 10.1016/j.funbio.2015.01.001

Staneck, J. L., and Roberts, G. D. (1974). Simplified approach to identification of aerobic actinomycetes by thin-layer chromatography. Appl. Microbiol. 28, 226-231.

Sui, J.-L., Xu, X.-X., Qu, Z., Wang, H.-L., Lin, H.-P., Xie, Q.-Y., et al. (2011). Streptomyces sanyensis sp. nov., isolated from mangrove sediment. Int. J. Syst. Evol. Microbiol. 61, 1632-1637. doi: 10.1099/ijs.0.023515-0

Sunesson, A.-L., Nilsson, C.-A., Carlson, R., Blomquist, G., and Andersson, B. (1997). Production of volatile metabolites from Streptomyces albidoflavus cultivated on gypsum board and tryptone glucose extract agar-influence of temperature, oxygen and carbon dioxide levels. Annal. Occup. Hyg. 41, 393-413. doi: 10.1016/S0003-4878(96)00046-4

Supriady, H., Kamarudin, M. N. A., Chan, C. K., Goh, B. H., and Kadir, H. A. (2015). SMEAF attenuates the production of pro-inflammatory mediators through the inactivation of Akt-dependent NF- $\kappa$ B, p38 and ERK1/2 pathways in LPS-stimulated BV-2 microglial cells. J. Funct. Foods 17, 434-448. doi: 10.1016/j.jff.2015.05.042

Takahashi, Y., Matsumoto, A., Seino, A., Iwai, Y., and Omura, S. (1996). Rare actinomycetes isolated from desert soils. Actinomycetologica 10, 91-97. doi: 10.3209/saj.10_91

Tamura, K., Stecher, G., Peterson, D., Filipski, A., and Kumar, S. (2013). MEGA6: molecular evolutionary genetics analysis version 6.0. Mol. Biol. Evol. 30, 2725-2729. doi: 10.1093/molbev/mst197

Tan, G., Gyllenhaal, C., and Soejarto, D. (2006). Biodiversity as a source of anticancer drugs. Curr. Drug Targets 7, 265-277. doi: $10.2174 / 138945006776054942$

Tan, L. T.-H., Ser, H.-L., Yin, W.-F., Chan, K.-G., Lee, L.-H., and Goh, B.-H. (2015). Investigation of antioxidative and anticancer potentials of Streptomyces sp. MUM256 isolated from Malaysia mangrove soil. Front. Microbiol. 6:1316. doi: $10.3389 /$ fmicb.2015.01316

Tanaka, M., Shin-Ya, K., Furihata, K., and Seto, H. (1995). Isolation and structural elucidation of antioxidative substances, carbazoquinocins A to F. J. Antibiot. 48, 326-328. doi: 10.7164/antibiotics.48.326

Thompson, J. D., Gibson, T. J., Plewniak, F., Jeanmougin, F., and Higgins, D. G. (1997). The CLUSTAL_X windows interface: flexible strategies for multiple sequence alignment aided by quality analysis tools. Nucleic Acids Res. 25, 4876-4882. doi: 10.1093/nar/25.24.4876

Valko, M., Rhodes, C., Moncol, J., Izakovic, M., and Mazur, M. (2006). Free radicals, metals and antioxidants in oxidative stress-induced cancer. Chem. Biol. Interact. 160, 1-40. doi: 10.1016/j.cbi.2005.12.009

Versalovic, J., Koeuth, T., and Lupski, R. (1991). Distribution of repetitive DNA sequences in eubacteria and application to finerpriting of bacterial enomes. Nucleic Acids Res. 19, 6823-6831. doi: 10.1093/nar/19. 24.6823

Waksman, S. A., and Henrici, A. T. (1943). The nomenclature and classification of the actinomycetes. J. Bacteriol. 46, 337.

Wayne, L., Brenner, D., Colwell, R., Grimont, P., Kandler, O., Krichevsky, M., et al. (1987). Report of the ad hoc committee on reconciliation of approaches to bacterial systematics. Int. J. Syst. Evol. Microbiol. 37, 463-464. doi: 10.1099/00207713-37-4-463

Whiton, R., Lau, P., Morgan, S., Gilbart, J., and Fox, A. (1985). Modifications in the alditol acetate method for analysis of muramic acid and other neutral and amino sugars by capillary gas chromatography-mass spectrometry with selected ion monitoring. J. Chromato. A 347, 109-120. doi: 10.1016/S0021-9673(01)95474-3

Williams, P. G. (2009). Panning for chemical gold: marine bacteria as a source of new therapeutics. Trends Biotech. 27, 45-52. doi: 10.1016/j.tibtech.2008.10.005

Williams, S. (1989). "Genus Streptomyces Waksman and Henrici 1943 , 339AL," in Bergey's Manual of Systematic Bacteriology, eds S. T. Williams, M. E. Sharpe, J. G. Holt (Baltimore, MD: Williams \& Wilkins), $2452-2492$.

Xiao, J., Wang, Y., Luo, Y., Xie, S.-J., Ruan, J.-S., and Xu, J. (2009). Streptomyces avicenniae sp. nov., a novel actinomycete isolated from the rhizosphere of the mangrove plant Avicennia mariana. Int. J. Syst. Evol. Microbiol. 59, 2624-2628. doi: 10.1099/ijs.0.009357-0

Xu, J., Wang, Y., Xie, S.-J., Xu, J., Xiao, J., and Ruan, J.-S. (2009). Streptomyces xiamenensis sp. nov., isolated from mangrove sediment. Int. J. Syst. Evol. Microbiol. 59, 472-476. doi: 10.1099/ijs.0.000497-0

Yang, T., Yang, X., Wang, X., Wang, Y., and Song, Z. (2013). The role of tomato products and lycopene in the prevention of gastric cancer: a meta-analysis of epidemiologic studies. Med. Hypotheses 80, 383-388. doi: 10.1016/j.mehy.2013.01.005

Zainal, N., Ser, H.-L., Yin, W.-F., Tee, K.-K., Lee, L.-H., and Chan, K.G. (2016). Streptomyces humi sp. nov., an actinobacterium isolated from soil of a mangrove forest. Antonie van Leeuwenhoek 109, 467-474. doi: $10.1007 /$ s10482-016-0653-1

Conflict of Interest Statement: The authors declare that the research was conducted in the absence of any commercial or financial relationships that could be construed as a potential conflict of interest.

Copyright (c) 2017 Law, Ser, Duangjai, Saokaew, Bukhari, Khan, Ab Mutalib, Chan, Goh and Lee. This is an open-access article distributed under the terms of the Creative Commons Attribution License (CC BY). The use, distribution or reproduction in other forums is permitted, provided the original author(s) or licensor are credited and that the original publication in this journal is cited, in accordance with accepted academic practice. No use, distribution or reproduction is permitted which does not comply with these terms. 